\title{
Overweight and Obesity in Eastern Mediterranean Region: Prevalence and Possible Causes
}

\begin{abstract}
Abdulrahman 0. Musaiger
Nutrition and Health Research Unit, Deanship of Scientific Research, University of Bahrain and Arab Center for Nutrition, P.O. Box 26923, Manama, Bahrain

Correspondence should be addressed to Abdulrahman O. Musaiger, amusaiger@gmail.com

Received 12 March 2011; Revised 30 June 2011; Accepted 30 June 2011

Academic Editor: Gianluca Iacobellis

Copyright ( 92011 Abdulrahman O. Musaiger. This is an open access article distributed under the Creative Commons Attribution License, which permits unrestricted use, distribution, and reproduction in any medium, provided the original work is properly cited.

The objective of this paper was to explore the prevalence of overweight and obesity among various age groups as well as discuss the possible factors that associated with obesity in the Eastern Mediterranean Region (EMR). A systematic review of published papers between 1990 and 2011 was carried out. Obesity reached an alarming level in all age groups of the EMR countries. The prevalence of overweight among preschool children( $<5$ years) ranged from $1.9 \%$ to $21.9 \%$, while the prevalence of overweight and obesity among school children ranged from $7 \%$ to $45 \%$. Among adults the prevalence of overweight and obesity ranged from $25 \%$ to $81.9 \%$. Possible factors determining obesity in this region include: nutrition transition, inactivity, urbanization, marital status, a shorter duration of breastfeeding, frequent snacking, skipping breakfast, a high intake of sugary beverages, an increase in the incidence of eating outside the home, long periods of time spent viewing television, massive marketing promotion of high fat foods, stunting, perceived body image, cultural elements and food subsidize policy. A national plan of action to overcome obesity is urgently needed to reduce the economic and health burden of obesity in this region.
\end{abstract}

\section{Introduction}

According to World Health Organization, the Eastern Mediterranean Region (EMR) refers to all Arab Countries, excluding Algeria, in addition to Afghanistan, Iran, and Pakistan.

Obesity has become an epidemic in many parts of the world. The World Health Organization has warned of the escalating epidemic of obesity that could put the population in many countries at risk of developing noncommunicable diseases (NCD). Available studies in Eastern Mediterranean countries indicate that obesity has reached at an alarming level among both children and adults. Consequently, the incidence of NCD is also very high and represents more than $50 \%$ of total causes of death in the $\operatorname{EMR}[1,2]$.

The high prevalence of NCD in EMR has a great impact on the health care system, economic and social situation in this region. Evidence suggests that even a moderate amount of weight loss can be useful in reducing levels of some risk factors for NCD [3]. Unfortunately, national intervention programmes to prevent and control obesity in EMR are relatively absent. Additionally, factors associated with the occurrence of obesity have not been well investigated, which in turn relatively affect the impact of any programmes to prevent obesity in this region.

Obesity is often defined simply as a condition of abnormal or excessive fat accumulation in adipose tissue, to the extent that health may be impaired [4]. Obesity is measured by various methods such as body mass index (BMI), waist circumference, waist-hip ratio, skinfold, and percent body fat measurements [5]. The majority of studies in the EMR countries used BMI, with a few of them using waist circumference to measure obesity. Skinfold anthropometry is not commonly used. This paper aimed to highlight the prevalence of overweight and obesity in the EMR countries and the possible causes of obesity, based on the literature review.

\section{Methods}

A systematic literature review of studies published in English between January 1990 and May 2011 using Medline database, 
PubMed Center, Google Scholar, and WHO Info Base was carried out. Health ministry and other official reports which included the prevalence of overweight and obesity among preschool children, school-aged children, adolescents, and adults were also covered.

Keywords used included overweight, obesity, anthropometric measurements, weight status, body mass index, fatness, risk factors, nutritional status, children, and adolescents for each country in the Eastern Mediterranean, separately. Keywords like Arab, Gulf, Middle, East and Eastern Mediterranean were also used in the searching process.

Over 2000 articles were identified primarily. The titles and abstracts of these articles were then reviewed to screen for publication that possibly addressed obesity and factors associated with it in the EMR. About 400 articles were identified at this stage.

For the findings on the prevalence of overweight and obesity, only studies published in English and based on a nationally representative sample of nationals were selected. Therefore, articles published on the prevalence of obesity in towns, urban, rural, or regional area in the country were excluded from prevalence tables (most of exclusion were in this category). If there were more than one national study in the same country, the recent one was included in the prevalence tables. Information gathered included sample size, country, demographic characteristics, definition of overweight, and/or obesity and the survey year. When the original study did not report the survey year, the publication year of the paper was used.

The definitions of obesity are varied from study to another, even in the same country. For adults, all studies used the body mass index (BMI, $\mathrm{kg} / \mathrm{m}^{2}$ ) recommended by World Health Organization (WHO) [4], as overweight defined as BMI $25-<30$ and obesity defined as BMI $\geq 30$. However, many adult studies included adolescents (15-18 years) which may provide less accurate estimation of the prevalence of overweight and obesity.

For children and adolescents, several definitions were used to define overweight and obesity such as International Obesity Task Force (IOTF) [6], Percentiles of National Health and Nutrition Examination Survey-1 (NHANES-1) [7], WHO growth chart [8], and growth chart of Center for Disease Control and Prevention [9].

For the factors associated with obesity, one to three examples for each factor were included, as possible. Selection of the factor was based on the sample size and the variation of countries to reflect the different socioeconomic background of these factors. The total numbers of articles included in this review, therefore, were about 115 articles related to obesity in EMR.

\section{Prevalence of Overweight and Obesity}

3.1. Obesity among Children and Adolescents. The prevalence of excess weight among children is increasing in both developed and developing countries, but at very different speeds and in different patterns [4]. Worldwide, over 22 million children under the age of 5 years are severely overweight, as are 155 million children of school age. This implies that one in 10 children worldwide is overweight. This global average reflects a wide range of prevalence level. It was estimated that about 23.5 million of school children age were overweight or obese in the Eastern Mediterranean Region during 1992-2001, and the proportion of school children is almost doubled in 2010, to 41.7 million. The prevalence of overweight and obesity in the EMR countries is the second in the world after the Americans and exceeds European countries [10].

\subsubsection{Prevalence in Preschool Children. Based on WHO/Info} [11], the prevalence of overweight among preschool children ( $\leq 5$ years) in EMR ranged from $2.3 \%$ in Palestine to $17.5 \%$ in Syria. This review showed similar pattern of overweight, but with some differences in the prevalence, mainly due to the source of data. Information provided in Table 1 indicated that the prevalence of overweight among children aged $0-5$ years was higher in most low- and middle-income countries compared to high-income countries. For example, the proportion of overweight in Arab Gulf countries (the richest countries in the EMR) among preschool children ranged from $1.9 \%$ to $9.4 \%$, whereas it was $12.3 \%$ in Djibouti and $21.9 \%$ in Syria.

The prevalence of obesity among preschool children has increased significantly during the past three decades. In Saudi Arabia, for example, Al-Hazzaa [12] showed that the prevalence of obesity among school boys aged 6-14 years has increased seven times during 1988 and 2005 (from $3.4 \%$ to $24.5 \%$, resp.). The percent of body fat increased by $6.5 \%$ for the same period. In general, all the anthropometric measurements increased during this period.

3.1.2. Prevalence in School Children and Adolescents. Although there are many studies on the prevalence of obesity among school children and adolescents in this region, the majority of the published data were not nationally representative and were more focused on specific areas in the country. It is worth noting that some data includes a wide age range for adolescents (i.e., 6 to 18 years) without taking into consideration the pre and puberty stage which has a significant influence on weight gain.

Available statistics indicate that the prevalence of overweight and obesity among school children is alarming in most countries of the region (Table 2). The prevalence of overweight ranged from $5.4 \%$ in Iran to $32 \%$ in Kuwait, whereas the prevalence of obesity ranged from $1.6 \%$ in Iran to $24.8 \%$ in Kuwait. In general, overweight was more prevalence than obesity in both males and females. However, the prevalence of overweight and obesity by sex in this age group does not exhibit the same trend. In countries, such as Bahrain, Egypt, Tunisia, Kuwait, and Qatar, the prevalence of overweight was higher among girls than boys. Obesity was also higher among adolescent girls than boys in Bahrain, Egypt, and Kuwait. In some countries such as Lebanon and United Arab Emirates (UAE), the prevalence of overweight and obesity was higher in boys than girls (Table 2). 
TABLE 1: National prevalence of overweight among preschool children ( $0-5$ years) in selected EMR countries.

\begin{tabular}{|c|c|c|c|c|c|c|c|}
\hline Country & Date of survey & Sample size & Sex & Age (year) & Definition & $\begin{array}{c}\% \\
\text { Overweight }\end{array}$ & References \\
\hline Afghanistan & 1997 & 4846 & $\mathrm{M} / \mathrm{F}$ & $0.5-2.99$ & NCHS/WHO (>2SD) & 4.0 & {$[13]$} \\
\hline \multirow{4}{*}{ Bahrain } & \multirow{4}{*}{2003} & 188 & $\mathrm{M}$ & $2-<4$ & IOTF & 9.5 & \multirow{4}{*}[14]{} \\
\hline & & 178 & $\mathrm{~F}$ & $2-<4$ & IOTF & 13.2 & \\
\hline & & 166 & M & $4-<6$ & IOTF & 10.3 & \\
\hline & & 166 & $\mathrm{~F}$ & $4-<6$ & IOTF & 10.4 & \\
\hline \multirow{2}{*}{ Djibouti } & \multirow{2}{*}{2002} & 780 & $\mathrm{M}$ & \multirow{2}{*}{$0-5$} & \multirow{2}{*}{$\mathrm{BMI} /$ age $>$ 2SD $(\mathrm{WHO})$} & 12.3 & \multirow{2}{*}[15]{} \\
\hline & & 757 & $\mathrm{~F}$ & & & 7.9 & \\
\hline Egypt & $1995-1996$ & 9766 & $\mathrm{M} / \mathrm{F}$ & $0-4.99$ & NCHS/WHO (>2SD) & 8.6 & {$[13]$} \\
\hline Jordan & 1990 & 6601 & $\mathrm{M} / \mathrm{F}$ & $0-4.99$ & NCHS/WHO (>2SD) & 5.7 & {$[13]$} \\
\hline \multirow{2}{*}{ Kuwait } & \multirow{2}{*}{2005} & 2508 & $\mathrm{M}$ & \multirow[t]{2}{*}{$2-59 \mathrm{~m}$} & \multirow{2}{*}{$\mathrm{wt} / \mathrm{ht}>2 \mathrm{SD}(\mathrm{WHO})$} & 5.2 & \multirow{2}{*}[16]{} \\
\hline & & 2405 & $\mathrm{~F}$ & & & 6.8 & \\
\hline \multirow{2}{*}{ Libya } & \multirow{2}{*}{2003} & 3608 & $\mathrm{M}$ & $0-5$ & \multirow{2}{*}{ BMI/age > 2SD (WHO) } & 13.9 & \multirow{2}{*}[15]{} \\
\hline & & 3624 & $\mathrm{~F}$ & $0-5$ & & 12.9 & \\
\hline \multirow{2}{*}{ Morocco } & \multirow{2}{*}{ 2003-2004 } & 2672 & M & $0-5$ & \multirow{2}{*}{$\mathrm{BMI} /$ age $>$ 2SD $(\mathrm{WHO})$} & 17.8 & \multirow{2}{*}[15]{} \\
\hline & & 2709 & $\mathrm{~F}$ & $0-5$ & & 13.2 & \\
\hline Oman & 1999 & 14144 & $\mathrm{M} / \mathrm{F}$ & $0-5$ & wt/ht > 2SD (WHO) & 1.9 & {$[17]$} \\
\hline Pakistan & $1990-1991$ & 4056 & $\mathrm{M} / \mathrm{F}$ & $0-4.99$ & NCHS/WHO (>2SD) & 3.1 & {$[13]$} \\
\hline \multirow{2}{*}{ Qatar } & \multirow{2}{*}{2001} & 4136 & $\mathrm{M}$ & $0-5$ & \multirow{2}{*}{$\geq 97$ percentiles (CDC) } & 8.9 & \multirow{2}{*}[18]{} \\
\hline & & 4095 & $\mathrm{~F}$ & $0-5$ & & 9.4 & \\
\hline \multirow{2}{*}{ Sudan } & \multirow{2}{*}{$2000-2001$} & 9018 & M & $0-4.99$ & \multirow{2}{*}{$\geq 2 Z$-scores $(\mathrm{WHO})$} & 3.0 & \multirow{2}{*}[19]{} \\
\hline & & 9025 & $\mathrm{~F}$ & $0-4.99$ & & 3.9 & \\
\hline \multirow{2}{*}{ Syria } & \multirow{2}{*}{2001} & 2804 & M & $0-5$ & $\mathrm{BMU} /$ age $>2 \mathrm{SD}(\mathrm{WHO})$ & 21.9 & \\
\hline & & 2650 & $\mathrm{~F}$ & $0-5$ & BMI/age > LSD (WHO $)$ & 18.4 & [15] \\
\hline Tunisia & 2006 & - & $\mathrm{M}$ & $0-4.99$ & wet/age $>2 \mathrm{SD}(\mathrm{WHO})$ & 5.6 & \\
\hline Iunisia & 2000 & - & $\mathrm{F}$ & $0-4.99$ & wt/age $>2 S D(W H U)$ & 7.2 & {$[20]$} \\
\hline & 2003 & 5658 & $\mathrm{M}$ & $0-5$ & & 9.3 & \\
\hline Yemen & 2003 & 5266 & $\mathrm{~F}$ & $0-5$ & $\mathrm{BMI} / \mathrm{age}>2 \mathrm{SD}(\mathrm{WHO})$ & 8.3 & {$[15]$} \\
\hline
\end{tabular}

Lobstein et al. [21] reported that there are many constraints on using survey data for interpreting trends in obesity in children and adolescents. These include unsimilarity of age grouping, not nationally representative sampling, large intra-and inter-population variation in the patterns of sexual maturation, secular trends in growth and development, high prevalence of stunting as stunted children are more likely to be overweight in countries undergoing a rapid nutrition transition, differences may exist in the timing and patterns of adiposity rebound between populations in particular between populations in industrialized and in developing countries and measuring errors.

Another important factor is the type of reference and cutoff used, as there are several reference data used to estimate obesity among school children, such as CDC, WHO, and IOTF references. Each reference gives a different prevalence of overweight and obesity. In Bahrain, for example, AlSendi et al. [22] used three difference set of criteria to estimate the prevalence of obesity among adolescents (12-17 years); NHANES-1, IOTF, and WHO standards. They found that there was a considerable variation in the prevalence of obesity between these standards. In general, WHO standard gave higher prevalence of obesity, but lower prevalence of overweight than other standards. Nonetheless, survey material is an invaluable source of data for understanding the rising epidemic of childhood obesity. The continued collection of such data is essential.

3.2. Prevalence in Adults. Using either BMI or waist-hip ratio as indicators of obesity, the prevalence of obesity in Eastern Mediterranean region is one of the highest in the world. Yusuf et al. [32] did a standardized case-control study on the association of obesity and myocardial infarction in 52 countries. They reported that the mean BMI was lowest in South Asia (24.9), China (24.4), and South Asia (24.0); intermediate in central and Eastern Europe (26.7), South America (26.7), Africa (26.7), and Western Europe (26.5); and highest in North America (27.7), the Middle East (27.4), and Australia and New Zealand (27.0). Striking variations could also be seen in the proportion of those with obesity (BMI $\left.>30 \mathrm{~kg} / \mathrm{m}^{2}\right)$ or overweight $\left(>25 \mathrm{~kg} / \mathrm{m}^{2}\right)$ in the various regions. 
TABLE 2: National prevalence of overweight and obesity among school children and adolescents in selected EMR countries.

\begin{tabular}{|c|c|c|c|c|c|c|c|c|}
\hline Country & $\begin{array}{l}\text { Date of } \\
\text { survey }\end{array}$ & $\begin{array}{l}\text { Sample } \\
\text { size }\end{array}$ & Sex & Age (year) & Definition & $\begin{array}{c}\text { Overweight } \\
\%\end{array}$ & Obesity \% & References \\
\hline Bahrain & 2006 & $\begin{array}{l}336 \\
396\end{array}$ & $\begin{array}{c}\mathrm{M} \\
\mathrm{F}\end{array}$ & $\begin{array}{l}15-18 \\
15-18\end{array}$ & $\begin{array}{c}\text { BMI/age } \geq \\
85 \mathrm{P}-<95 \mathrm{P} / \geq 95 \mathrm{P} \\
(\text { NHANES }-1)\end{array}$ & $\begin{array}{l}15.8 \\
17.4\end{array}$ & $\begin{array}{l}13.7 \\
19.4\end{array}$ & {$[23]$} \\
\hline Egypt & 2004 & $\begin{array}{l}2969 \\
3049\end{array}$ & $\begin{array}{c}\mathrm{M} \\
\mathrm{F}\end{array}$ & $\begin{array}{l}10-18 \\
10-18\end{array}$ & BMI/age NCHS/CDC & $\begin{array}{l}11.5 \\
15.2\end{array}$ & $\begin{array}{l}6.5 \\
7.7\end{array}$ & {$[24]$} \\
\hline Iran & $2003-2004$ & $\begin{array}{l}10.253 \\
10.858\end{array}$ & $\begin{array}{c}\mathrm{M} \\
\mathrm{F}\end{array}$ & $\begin{array}{l}6-18 \\
6-18\end{array}$ & IOTF & $\begin{array}{l}5.4 \\
5.9\end{array}$ & $\begin{array}{l}1.6 \\
1.3\end{array}$ & {$[25]$} \\
\hline Kuwait & 2006 & $\begin{array}{l}2657 \\
2745\end{array}$ & $\begin{array}{c}\mathrm{M} \\
\mathrm{F}\end{array}$ & $\begin{array}{l}10-14 \\
10-14\end{array}$ & IOTF & $\begin{array}{l}29.3 \\
32.1\end{array}$ & $\begin{array}{l}14.9 \\
14.2\end{array}$ & {$[26]$} \\
\hline & 2001-2005 & $\begin{array}{l}1630 \\
1611\end{array}$ & $\begin{array}{c}M \\
F\end{array}$ & $\begin{array}{l}14-19 \\
14-19\end{array}$ & IOTF & $\begin{array}{l}18.8 \\
25.3\end{array}$ & $\begin{array}{l}24.8 \\
20.0\end{array}$ & {$[16]$} \\
\hline Lebanon & $1995-96$ & $\begin{array}{l}257 \\
336 \\
\end{array}$ & $\begin{array}{c}\mathrm{M} \\
\mathrm{F}\end{array}$ & $\begin{array}{l}10-19 \\
10-19 \\
\end{array}$ & BMI/age (NHANES-1) & $\begin{array}{l}26.9 \\
14.7 \\
\end{array}$ & $\begin{array}{l}7.7 \\
2.9 \\
\end{array}$ & {$[27]$} \\
\hline Qatar & $2003-2004$ & $\begin{array}{l}1056 \\
2690 \\
1084 \\
2612 \\
\end{array}$ & $\begin{array}{c}M \\
M \\
F \\
F\end{array}$ & $\begin{array}{c}6-9 \\
10-18 \\
6-9 \\
10-18\end{array}$ & IOTF & $\begin{array}{l}16.3 \\
27.5 \\
15.5 \\
20.0\end{array}$ & $\begin{array}{l}3.5 \\
7.1 \\
2.8 \\
3.9 \\
\end{array}$ & {$[28]$} \\
\hline Saudi Arabia & 2005 & $\begin{array}{l}6149 \\
5917 \\
3659 \\
3592\end{array}$ & $\begin{array}{c}\text { M } \\
F \\
M \\
F\end{array}$ & $\begin{array}{c}5-12 \\
5-12 \\
13-18 \\
13-18\end{array}$ & $\begin{array}{l}\mathrm{BMI} / \text { age }>1 \mathrm{SD} />2 \mathrm{SD} \\
(\mathrm{WHO})\end{array}$ & $\begin{array}{l}19.9 \\
19.2 \\
24.8 \\
28.4\end{array}$ & $\begin{array}{c}7.8 \\
11.0 \\
13.8 \\
12.1\end{array}$ & [29] \\
\hline Tunisia & 2005 & $\begin{array}{l}1295 \\
1577\end{array}$ & $\begin{array}{c}M \\
F\end{array}$ & $\begin{array}{l}15-19 \\
15-19\end{array}$ & IOTF & $\begin{array}{l}17.4 \\
20.4\end{array}$ & $\begin{array}{l}4.1 \\
4.4\end{array}$ & {$[30]$} \\
\hline UAE & 2005 & $\begin{array}{l}7741 \\
7888\end{array}$ & $\begin{array}{c}M \\
F\end{array}$ & $\begin{array}{l}10-19 \\
10-19\end{array}$ & IOTF & $\begin{array}{l}21.2 \\
21.7\end{array}$ & $\begin{array}{l}13.2 \\
11.0\end{array}$ & {$[31]$} \\
\hline
\end{tabular}

Data for waist-to-hip ratio in the various regions indicated a different pattern compared with BMI. Mean waisthip ratio was lowest in China (0.88); intermediate in North America (0.90), Southeast Asia (0.89), Europe (0.91), Africa (0.92), and South Asian countries (0.89); but highest in the Middle East (0.93) and South America (0.94). In women, the highest BMI and waist-hip ratio was recorded in the Middle East (BMI of 29.5, waist-hip ratio of 0.92 ). By contrast, the highest BMI in men was in North America (28.3), and the highest wais-hip ratio was in South America (0.96). Thus, dependent on whether BMI or waist-to-hip ratio is used, there is considerable difference in the proportion of obesity in different regions [32].

In general, the prevalence of obesity in adults has almost double than adolescence, creating a great burden on the health care in these countries. The prevalence of overweight in men ranged from $19.2 \%$ in Libya to $51.7 \%$ in Tunisia. The corresponding proportion in women was $21.1 \%$ in Libya and $71 \%$ in Tunisia. As for obesity, the prevalence ranged from $5.7 \%$ in Morocco to 39\% in Kuwait for men and ranged from $7.1 \%$ in Libya to $53 \%$ in Kuwait for women (Table 3).

The mean BMI among men was the highest in Kuwait $\left(27 \mathrm{~kg} / \mathrm{m}^{2}\right)$ and lowest in Somalia $\left(20.7 \mathrm{~kg} / \mathrm{m}^{2}\right)$. A similar trend was seen among women, as the mean BMI was $31 \mathrm{~kg} / \mathrm{m}^{2}$ in Kuwait and $21.8 \mathrm{~kg} / \mathrm{m}^{2}$ in Somalia (Table 4)
Several conclusions can be drawn from these data. (1) Overweight is more likely to be prevalent among men than women in most EMR countries. (2) Obesity is more prevalent among women in all countries of the EMR. (3) The mean BMI for women is higher than that for men in all countries in the EMR. (4) The data of overweight and obesity are relatively more reliable than that of children and adolescents; this is due to the inclusion of nationalbased data, as well as the use of the same cutoff to measure overweight and obesity. (5) Poor countries such as Djibouti, Somalia, Sudan, and Yemen showed a high prevalence of overweight, but not of obesity. This may predict a future increase of obesity if no measure is taken to control it. (6) In all high and middle income countries in the EMR, overweight and obesity has become a major public health problem, with a prevalence higher than many of developed countries. This creates the need for urgent action to prevent and control obesity in EMR countries.

\section{Factors Associated with Obesity in the EMR Countries}

Based on epidemiological studies, the WHO [42] has divided the evidence for factors that might promote or protect 
TABLE 3: National prevalence of overweight (BMI $\geq 25-29.9)$ and obesity (BMI $\geq 30)$ among adults in selected EMR countries.

\begin{tabular}{|c|c|c|c|c|c|c|c|}
\hline Country & Date of survey & Sample size & Sex & Age (year) & $\%$ Overweight & $\%$ Obesity & References \\
\hline \multirow{2}{*}{ Bahrain } & \multirow{2}{*}{2007} & 863 & $\mathrm{M}$ & \multirow{2}{*}{$20-65$} & 34.8 & 32.3 & \multirow{2}{*}[33]{} \\
\hline & & 906 & $\mathrm{~F}$ & & 31.1 & 40.3 & \\
\hline \multirow{2}{*}{ Iran } & \multirow{2}{*}{ 2004-2005 } & 45082 & $\mathrm{M}$ & \multirow{2}{*}{$15-65$} & 42.8 & 11.1 & \multirow{2}{*}[34]{} \\
\hline & & 44322 & $\mathrm{~F}$ & & 57.0 & 25.2 & \\
\hline \multirow{2}{*}{ Kuwait } & \multirow{2}{*}{2007} & 918 & $\mathrm{M}$ & \multirow{2}{*}{$20-65$} & 38.9 & 39.2 & \multirow{2}{*}[35]{} \\
\hline & & 1362 & $\mathrm{~F}$ & & 28.9 & 53.0 & \\
\hline \multirow{2}{*}{ Lebanon } & \multirow{2}{*}{ 1995-96 } & 501 & M & \multirow{2}{*}{$20-70$} & 43.4 & 14.3 & \multirow{2}{*}[27]{} \\
\hline & & 715 & $\mathrm{~F}$ & & 30.6 & 15.5 & \\
\hline \multirow{2}{*}{ Libya } & \multirow{2}{*}{2000} & 334 & $\mathrm{M}$ & \multirow{2}{*}{$15-50$} & 19.2 & 5.8 & \multirow{2}{*}[36]{} \\
\hline & & 350 & $\mathrm{~F}$ & & 21.1 & 7.1 & \\
\hline \multirow{2}{*}{ Morocco } & \multirow{2}{*}{ 1998-99 } & 9120 & $\mathrm{M}$ & \multirow{2}{*}{$18+$} & 28.0 & 5.7 & \multirow{2}{*}[37]{} \\
\hline & & 8200 & $\mathrm{~F}$ & & 33.0 & 18.3 & \\
\hline \multirow{2}{*}{ Oman } & \multirow{2}{*}{2000} & 3076 & $\mathrm{M}$ & \multirow{2}{*}{$20-70$} & 30.6 & 15.5 & \multirow{2}{*}[38]{} \\
\hline & & 3367 & $\mathrm{~F}$ & & 27.2 & 22.3 & \\
\hline Palestine & 2002 & 1534 & $\mathrm{~F}$ & $15-49$ & - & 10.9 & {$[39]$} \\
\hline \multirow{2}{*}{ Saudi Arabia } & \multirow{2}{*}{2005} & 1658 & M & \multirow{2}{*}{$25-65$} & 43.0 & 31.5 & \multirow{2}{*}[40]{} \\
\hline & & 1621 & $\mathrm{~F}$ & & 28.8 & 50.4 & \\
\hline \multirow{2}{*}{ Tunisia } & \multirow{2}{*}{2005} & 2379 & $\mathrm{M}$ & \multirow{2}{*}{$35-70$} & 51.7 & 37.0 & \\
\hline & & 2964 & $\mathrm{~F}$ & & 71.1 & 13.3 & {$[41]$} \\
\hline
\end{tabular}

TAble 4: BMI $\left(\mathrm{kg} / \mathrm{m}^{2}\right)$ among adults in Eastern Mediterranean Region.

\begin{tabular}{lcc}
\hline \multirow{2}{*}{ Country } & \multicolumn{2}{c}{ Mean BMI } \\
\hline Bahrain & 26.4 & Female \\
Djibouti & 21.8 & 27.9 \\
Egypt & 26.7 & 22.9 \\
Iran (Islamic Republic of) & 24.9 & 29.6 \\
Iraq & 24.1 & 26.5 \\
Jordan & 26.1 & 25.2 \\
Kuwaiti & 27.5 & 27.9 \\
Lebanon & 25.3 & 31.0 \\
Libyan Arab Jamahiriya & 25.0 & 26.2 \\
Morocco & 23.2 & 26.1 \\
Oman & 24.2 & 25.8 \\
Pakistan & 22.0 & 24.9 \\
Qatar & 26.0 & 22.3 \\
Saudi Arabia & 26.7 & 27.1 \\
Somalia & 20.7 & 27.6 \\
Sudan & 21.6 & 21.8 \\
Syrian Arab Republic & 24.9 & 22.7 \\
Tunisia & 24.4 & 26.1 \\
United Arab Emirates & 27.0 & 26.9 \\
Yemen & 22.6 & 28.6 \\
\hline Source WHO & & 22.8 \\
\hline
\end{tabular}

Source: WHO [11].

against overweight and weight gain into four categories: convincing, probable, possible, and insufficient. Energy intake and inactivity are among the most convincing factors to be associated with the occurrence of obesity. Home and school environment, heavy marketing of energy dense foods, and unsuitable social and economic environment are the most probable factors related to weight gain.

Comprehensive and in-depth studies related to factors determine obesity in the EMR countries are very few. Most of studies are cross-sectional and focused on limited factors. The uses of various format of questionnaires in the studies make interpretation and the comparison between the countries, and even in the same country, a difficult task.

4.1. Nutrition Transitions/Change in Food Consumption. Economic improvement over the last 50 years in most of the EMR countries has resulted in greater affluence and to diets that are higher in fats especially saturated fat, cholesterol, and refined carbohydrates and low in polyunsaturated fatty acids and dietary fiber. This nutrition trend has also been accompanied with a sedentary lifestyle and increased level of stress. Consequently, the prevalence of obesity and other noncommunicable diseases has risen steeply $[43,44]$.

The nutrition transition can be noticed in all high income countries in the region (Arab Gulf Countries), and most middle income countries, especially in urban areas, and in some high or socioeconomic sectors of poor countries. Several studies have reported the association of dietary patterns with obesity and central adiposity; most of these came from Western countries, and there are few data available from developing countries, especially from EMR countries $[44,45]$.

Food consumption patterns and dietary habits in the EMR countries have changed markedly during the past four 
decades. There has been an increase in per capita energy and fat intake in all countries. Data from food balance sheets showed an increase in calories supply during 1971-2005 in these countries, and the percentage of calorie which came from animal foods has markedly increased. The daily per capita energy supply showed high increases ranging from $16 \%$ in Jordan to $60 \%$ in Saudi Arabia, during the same period [46].

In general, the contribution of carbohydrates to the Daily Energy Supply (DES) decreased as the per capita income of the country increased. In contrast, the contribution of fat to DES increased with income. The contribution of sugar to DES is relatively high in all EMR countries ranging from $9 \%$ to $15 \%$ (Table 5 ).

Mokhtar et al. [37] has observed a significant increase in body weight (based on BMI) with the increase in total energy and macronutrient intake among Tunisian and Moroccan women. The total energy intake of Moroccan women rose significantly $(P<0.05)$ from $1976 \mathrm{kcal}$ to $2530 \mathrm{kcal}$ among those who have $\mathrm{BMI}<18.5$ and $\mathrm{BMI} \geq 30$, respectively; an increase of about $41 \%$ in daily calories intake. A similar trend was seen in Tunisian women, with corresponding figures of 2124 and $2330 \mathrm{kcal}$, respectively $(P<0.05)$. The intake of macronutrients showed similar tendencies, as all of them increased with weight increase.

It is most likely, that the high consumption of foods rich in fat and calories and the sedentary lifestyle among communities in the EMR have played an important role in the rise of obesity. This is particularly true with the great shift from traditional foods to more westernized foods in these countries. In Jordan, it was found that $40 \%$ of energy intake of obese school children (6-12 years) came from fat intake, compared of $28 \%$ among nonobese children. There was no significant difference in energy from protein, but the proportion of energy intake from carbohydrates was less among obese (44\%) than nonobese (58\%) [47]. This may imply that the high intake of fat-rich foods by obese children was related to obesity.

Similar findings were seen among adults. Esamillzadeh and Azadbakht [48] studied the relationship between three dietary patterns and obesity among 486 women aged 40-60 years in Iran. The three major dietary patterns were healthy, Western and Iranian dietary patterns. Their findings suggest that a dietary pattern characterized by high consumption of fruits, vegetables, poultry, and legumes is associated with lower risk of general and central obesity, while a dietary pattern with high amounts of refined grains, red meat, butter, processed meat, and high-fat dairy products and low amounts of vegetables and low-fat dairy products is associated with increased risk of these conditions.

There is good evidence that there is an inverse association between fruit/vegetable consumption and weight gain [49]. Studies in the EMR indicated a low intake of fruit and vegetables among children [50, 51] and adults [52]. In Lebanon, Nasreddine et al. [50] found that energy intake from fruit was found to be significantly higher amongst normal weight adolescents (15-18 years) from Damascus, Syria, than their overweight counterparts $(P<0.05)$. In another comprehensive study on 21,111 school students (6-
TABle 5: Contribution (percentage) of nutrients to Daily Energy Supply (DES) in the EMR Countries.

\begin{tabular}{lccc}
\hline Nutrients & $\begin{array}{c}\text { Low-income } \\
\text { countries }\end{array}$ & $\begin{array}{c}\text { Intermediate- } \\
\text { income } \\
\text { countries }\end{array}$ & $\begin{array}{c}\text { High-income } \\
\text { countries }\end{array}$ \\
\hline Carbohydrates & $55-75$ & $60-70$ & $59-60$ \\
Fats & $15-20$ & $20-25$ & $29-30$ \\
Proteins & $10-12$ & $10-11$ & $10-12$ \\
Complex & $60-70$ & $50-60$ & $45-50$ \\
carbohydrates & $3-12$ & $9-12$ & $10-15$ \\
Sugar & $4-7$ & $4-10$ & $11-15$ \\
Animal fat & $60-80$ & $45-65$ & $35-40$ \\
Cereals & & &
\end{tabular}

FAO [46].

18 years), in Iran, Kelishadi et al. [51] reported that a higher intake of fruit and vegetables had a significant negative association with increase in BMI. A study among university students in Kuwait revealed that regular consumption of fruit and vegetables was protective factor for obesity (odd ratio (OR) $0.55,95 \%$ confidence interval (CI) $0.20-1.40$, and 0.55 , 95\% CI, 0.30-2.24, for fruit and vegetables, resp.) [52].

Among adults, Dastgiri et al. [53] found that fruit consumption decrease the risk of obesity in both Iranian women and men $(\mathrm{OR}=0.60,95 \% \mathrm{CI}: 0.49-0.71$ versus $\mathrm{OR}=$ 0.62, 95\% CI: $0.51-0.74$, resp.). The same significant pattern was noted for the consumption of green vegetables $(\mathrm{OR}=$ $0.71,95 \%$ CI: $0.57-0.63$ versus OR $=0.86,95 \%$ CI: $0.77-0.98$ for women and men, resp.).

The trend toward the consumption of fast foods, especially among children and youths may increase the energy intake and consequently increase the risk for overweight [54]. Limited studies investigated the relationship between fast food intake and obesity in the EMR countries.

When the significant variables associated with obesity (physical activity, frequency of fast food, sweet consumption, and sedentary lifestyle) among university students in Kuwait (mean age $21.1 \pm 2.95$ years) were included in the model of Stepwise regression analysis, regular consumption of fast food was the most significant predictor of obesity among this age group $(P<0.01)$ [52].

However, it is difficult to blame the Western fast foods per se as a factor for consuming high amount of energydense foods, with the absence of well-designed studies on the role of fast foods in obesity in EMR. It is worth mentioning that many local foods consumed in this region contain a considerable amount of fat and energy. In a study to compare the nutritional profile of Western and local fast foods consumed in Bahrain, it was found that some local fast foods have higher proportion of fat, salt, and calories than Western fast foods. It was concluded that the conception that local foods are healthier than Western fast foods is not true, and, hence, nutrition education programmes should focus on the nutritional aspects of both local and Western fast foods [55]. 
4.2. Socioeconomic Status. Monteiro et al. [56] demonstrated that obesity in developing countries is no longer considered solely a disease of groups with higher socioeconomic status. The burden of obesity in each developing country tends to shift towards the groups with lower socioeconomic status (SES) as the country's gross national product (GNP) increases. The shift of obesity towards women with low SES apparently occurs at an earlier stage of economic development than it does for men.

In Pakistan, the prevalence of obesity increased as socioeconomic (SES) status increased, in both urban and rural areas. For example, the proportion of obesity in urban areas was 21\% among those aged 25-64 years and belonged to low SES. The proportion increased to $27 \%$ and $42 \%$ among middle and high SES, respectively [56].

Income is one of the most important socioeconomic indicators, which may be associated with obesity. By dividing the EMR countries in three groups, low, middle, and high income countries, it was found that obesity, in general, increased among both men and women as per capita income of the country increased. However, some of the middle-income countries, such as Egypt and Jordan have a high prevalence of obesity which is similar to high-income countries (Figure 1).

In most of the EMR countries, obesity is more prevalent in urban sectors than in rural sectors. Urbanization means decreased levels of physical activity and increase availability of food, as well as exposure to fast foods. Another change in lifestyle between urban and rural area is the increased exposure to western media in urban settings, which influence the urban people to match with western ways of life [57].

The prevalence of overweight in urban area of Egypt, for example, was $45.3 \%$ and $39.6 \%$ among men and women, respectively, compared to $28 \%$ and $36.5 \%$ in rural areas, respectively. The corresponding proportions were $20 \%$ and $45.2 \%$ in urban, and $6 \%$ and $20.8 \%$ in rural areas for men and women, respectively [58]. Similar trend was observed in Iran, Morocco, Oman, Palestine, and Saudi Arabia (Table 6). After adjusting for possible confounding factors including demographic and socioeconomic factors in a binary regression model, urban dwelling in Iran remained the major determinant of obesity (odd ratio $2.62, P<0.001$ ) [59].

In Palestine, it was found that the BMI levels of urban women and men were significantly higher than those of their rural counterparts $(P<0.004$ for both). When adjusted to the age, the prevalence of obesity (BMI $\geq 30$ ) was $35 \%$ and $18 \%$ in rural women and men, respectively, compared to $46 \%$ and $29 \%$ in their urban counterparts, respectively. The high proportion of obesity among urban residence in Palestine could be explained by the type of food consumed and low activity level, as urban people were more likely to consume high-fat foods, especially red meat, vegetable oils, and dairy products [60].

In regard to age groups, obesity increased as age increased in most EMR countries up to 60 years of age when obesity declined. This phenomenon was seen among both men and women. Several studies in the EMR countries have shown that the employment status of women (but not men) is

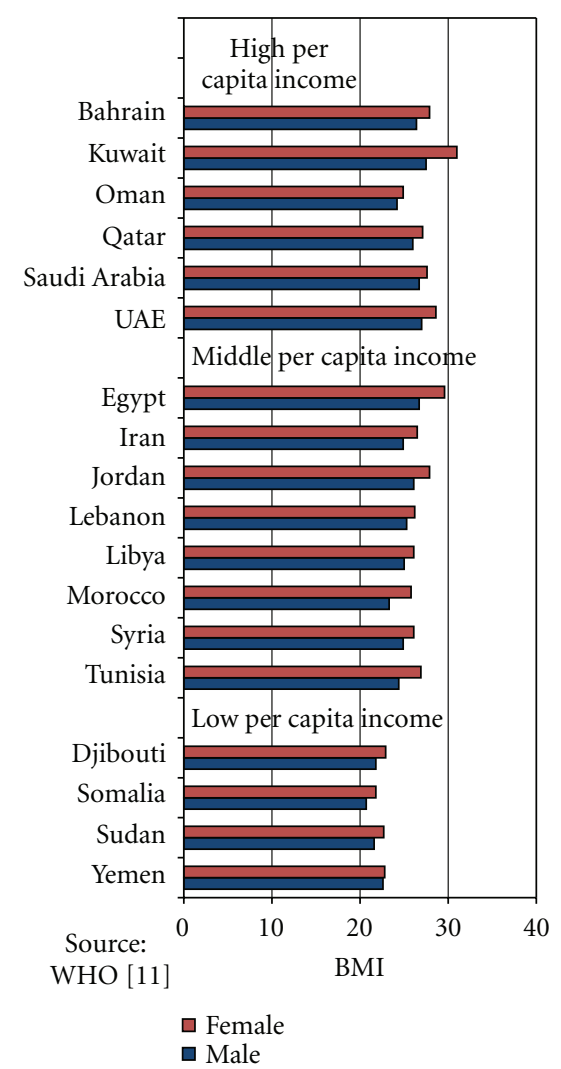

Figure 1: Mean BMI $\left(\mathrm{kg} / \mathrm{m}^{2}\right)$ among adults in EMR countries according to per capita income level.

significantly associated with weight gain [62-64]. Working women were less likely to be overweight than nonworking women. For example, in Saudi Arabia, Musaiger and AlAhdal [65] found that 55.9\% of nonworking women were obese, and the rest (44.1\%) were nonobese. This may be due to the fact that working women are generally young and unmarried. It is believed that the exposure of working women to the community at work may possibly put pressure on them to take more care of their weight [66].

In general, married women or men in the region were more likely to be overweight than unmarried ones. In Iran, Janghorbani et al. [34] found that age-adjusted means of BMI for married men $(25.0 \pm 0.03 \mathrm{SE})$ and women $(27.1 \pm$ $0.03 \mathrm{SE}$ ) were significantly higher than that for single men $(23.3 \pm 0.03 \mathrm{SE})$ and women $(24.3 \pm 0.07 \mathrm{SE})$. Similar trends in findings were observed in several studies in the EMR countries [67-69]. This may be due to a decrease in activity and increase in food intake after marriage. Fouad et al. [70] gave two possible explanations for these findings in Syria; married people are more likely to be physically inactive, and it is also possible that marriage increases cues and opportunities for eating because they tend to eat together and thus reinforce each other's increased intake. However, multiparity may be another reason for obesity among women, as a linear association was observed between parity (repeated pregnancy) and prevalence of obesity $(P<0.001)$. 
TABLE 6: Prevalence of overweight $(B M I \geq 25)$ and obesity $(B M I \geq 30)$ among adults in urban and rural areas in selected EMR countries.

\begin{tabular}{|c|c|c|c|c|c|c|c|c|}
\hline \multirow{2}{*}{ Country } & \multirow{2}{*}{ Date of survey } & \multirow{2}{*}{ Sample size } & \multirow{2}{*}{ Gender } & \multicolumn{2}{|c|}{ \% Overweight } & \multicolumn{2}{|c|}{ \% Obesity } & \multirow{2}{*}{ Reference } \\
\hline & & & & $\mathrm{U}^{*}$ & $\mathrm{R}^{*}$ & $\mathrm{U}$ & $\mathrm{R}$ & \\
\hline \multirow{2}{*}{ Egypt } & \multirow{2}{*}{ 1998-1999 } & 1974 & $\mathrm{M}$ & 45.3 & 28.1 & 20.0 & 6.0 & \multirow{2}{*}[58]{} \\
\hline & & 2909 & $\mathrm{~F}$ & 39.6 & 36.5 & 45.2 & 20.8 & \\
\hline \multirow{2}{*}{ Iran } & \multirow{2}{*}{ 2004-2005 } & 45082 & M & 35.3 & 25.9 & 12.4 & 8.1 & \multirow{2}{*}[34]{} \\
\hline & & 44322 & $\mathrm{~F}$ & 34.2 & 29.2 & 27.1 & 19.8 & \\
\hline \multirow{2}{*}{ Morocco } & \multirow{2}{*}{ 1998-1999 } & 6878 & M & 24.1 & 17.0 & 4.7 & 3.8 & \multirow{2}{*}[45]{} \\
\hline & & 7153 & $\mathrm{~F}$ & 31.1 & 25.8 & 19.1 & 11.1 & \\
\hline \multirow{2}{*}{ Oman } & \multirow{2}{*}{2000} & 3076 & M & 31.5 & 28.2 & 17.0 & 11.4 & \multirow{2}{*}[38]{} \\
\hline & & 3367 & $\mathrm{~F}$ & 27.3 & 27.2 & 25.1 & 14.7 & \\
\hline \multirow{2}{*}{$\begin{array}{l}\text { Palestine } \\
\text { (West Bank) }\end{array}$} & \multirow{2}{*}{2003} & 387 & M & - & - & 30.6 & 18.1 & \multirow{2}{*}[60]{} \\
\hline & & 549 & $\mathrm{~F}$ & - & - & 49.1 & 36.8 & \\
\hline Saudi Arabia & 1995-2000 & $8215 / 9008$ & $\mathrm{M} / \mathrm{F}$ & 36.9 & 36.9 & 39.7 & 27.0 & {$[61]$} \\
\hline
\end{tabular}

${ }^{*} \mathrm{U}$ : urban, R: rural.

Data from EMR region suggest that the association between education and obesity is controversial. Several confounding factors may interfere with this association such as age, marital status, rural-urban and income. However, more investigation is needed to explore the role of socioeconomic status in the prevalence of obesity in the EMR countries. It can be concluded that obesity is more prevalent, in middle aged, unemployed, married, and urban resident in this region.

4.3. Breastfeeding. Breastfeeding has been reported as being a potentially protective factor against weight gain in childhood. This is an important because overweight children are at risk of becoming overweight adults [71]. In Iran, Kelishadi et al. [72] found that the mean duration of breastfeeding among nonobese adolescents was significantly higher than obese adolescents (18.1 versus 12.4 months, resp.; $P<0.04$, $95 \%$ CI, 5.7-6.2). They also found that the use of commercial baby foods in infancy was lasted longer among obese (45.2 months) than nonobese adolescents (37.1 months) $(P<$ 0.02, 95\% CI, 6.1-6.7). In Egypt, Farahat et al. [73] reported that $41 \%$ of normal children aged 4-6 years were breastfed compared to $28 \%$ of overweight children. Additionally, they found that $38 \%$ of normal children were bottle fed, compared to $50 \%$ of overweight children $(P<0.05)$.

In Bahrain, it was showed that the median duration of breastfeeding was 12 months among nonobese preschool children (1-3 years), compared to 9 months among obese children $(P<0.01)$ [74]. Fallahzadeh et al. [75] showed a markedly lower overweight prevalence among breastfed than non-breastfed children in Iran. Children breastfed for at least 24 months were substantially less likely to be overweight than children breastfed for less than 12 months (OR 0.56, 95\% CI 0.31-0.9). A longer overall duration of breastfeeding and duration of exclusive breastfeeding were associated significantly with a decreased prevalence of overweight.

In Kuwait, it was reported that neither breastfeeding nor duration of breastfeeding was associated with childhood obesity at 3-6 years when potential confounders were controlled for. However, introduction of solid foods to the infants before two months was significantly associated with obesity, as children received solid foods before 2 months of age were two times at risk of being overweight than those who received solid foods between 4 and 6 months (odd ratio 2.39, $P<0.01)[76]$.

4.4. Snacking/Frequency of Eating. There is no specific definition of snacking, but many studies in the region have considered snacking as eating between meals, especially eating between breakfast and lunch (morning snacking) and between lunch and supper (evening snacking) [77]. Some studies in the Western World indicated that as snacking increases, the total energy intake increases. Snacks contribute to about $20-75 \%$ of total energy intake in western countries like US and UK [78]. However, there is little evidence that a higher frequency of eating per se is a potential cause of obesity. WHO [42] reported that there is insufficient evidence that increased eating frequency leads to increased or decreased obesity.

A number of cross-sectional studies in the EMR showed a negative relationship between snacking and obesity. In UAE, Bin Zaal et al. [77] showed that $60.5 \%$ of male adolescents (12-17 years) who always took snacks between breakfast and lunch were obese compared to $39.5 \%$ of nonobese adolescents, but the difference was not statistically significant $(P=0.149)$. However, the corresponding proportion among females was statistically significant $(P<0.044)(68.2 \%$ and $31.8 \%$, resp.). They concluded that snacking between breakfast and lunch was a protective factor for obesity among these adolescents. Snacking between lunch and supper was found to be protective for obesity among males $(\mathrm{OR}=0.5$, $95 \%$ CI $0.2-1.0$ ), but not among females ( $\mathrm{OR}=1.2,95 \% \mathrm{CI}$ $0.6-2.2)$.

In a study on 2000 adolescents aged between 11 and 18 years in Iran, Kelishadi et al. [72] revealed that the mean frequency of intake of bread, rice, fast food, pasta, and fatty snack was significantly higher among obese than nonobese 
adolescents. However, the intake of vegetable and fruits was significantly higher in nonobese adolescents than obese.

Kerkadi [79] showed that $30 \%$ of female university students in UAE who eat more than 3 meals per day were overweight or obese, whereas the remaining 70\% were underweight or normal. Among adults, Musaiger and AlAhdal [65] indicated that skipping snacking is positively associated with obesity, with $65.5 \%$ of Saudi women who skipped morning snacking being obese $(P<0.001)$, and $70.9 \%$ of those skipping evening snack being obese $(P<$ $0.001)$.

4.5. Skipping Breakfast. Skipping breakfast or intake of a poor nutritional value breakfast is common among both children and adults. Recent systematic review of 16 studies from Europe has showed that eating breakfast is associated with a reduced risk of becoming overweight or obese and a reduction in the BMI in children and adolescents [80].

In general, the percentage of skipping breakfast in the EMR countries is higher among girls than boys and increases with age. In the UAE, it was reported that $28 \%$ of boys aged 6-7 years skipped their breakfast compared to $37 \%$ of girls at same age. In Bahrain, about $42 \%$ and $59 \%$ of school boys and girls aged 10-15 years skipped their breakfast, respectively. In Saudi Arabia, 74\% of school girls aged 12-16 years skipped or irregularly consume breakfast [47]. Almost equal percentage of Lebanese males (32.2\%) and females (31.5\%) university students consumed their breakfast daily, while the rest either consumed it irregularly or did not consume it [81].

Studies in the relationship between breakfast intake and obesity in EMR are few and all of them are cross-sectional. In UAE, Kerkadi [79] found that $72.2 \%$ of nonobese female university students eat their breakfast regularly, and the rest (25.8\%) were either overweight or obese. Among adults, it was reported that $68.7 \%$ of Saudi women who skipped breakfast were obese, and the rest $(31.3 \%)$ were nonobese $(P<0.007)[65]$.

4.6. Sugary Beverages. The intake of sugar-sweetened beverages has continued to rise globally. Epidemiologic studies in the Western countries have provided substantial evidence that regular consumption of sugar-sweetened beverages, not only contribute to weight gain, but also increases risk of type 2 diabetes and metabolic syndrome [82, 83]. Sayegh et al. [84] studied the drinking habits of children aged 4-5 years in Jordan. They found that the consumption of sugar drinks is high among these children. Carbonated beverages are their favorite drinks with $60.7 \%$ of boys and $54.8 \%$ of girls consuming such drinks. Canned fruit juice came next, followed by fresh fruit juice. Another study in Jordan showed that the consumption of canned drinks by school children (6-12 years) was higher among obese (50\%) than nonobese children (15\%) [85]. Among adults, Rasheed [86] found that frequent snacking and regular drinking of soft drinks was significantly more common among Saudi obese women than nonobese women $(P<0.05)$.

In general, well-designed studies on the relationship between intake of sugary beverages and obesity in the
EMR are lacking, and, therefore, it is difficult to draw any conclusion regarding this matter.

4.7. Eating Out. In most EMR countries, the frequency of eating food prepared outside the home is increasing, and this is more apparent in the GCC countries, as well as, in some middle-income countries [87]. In Syria, for example, Bashour [88] indicated that $67.4 \%$ of male adolescents (aged 13-18 years) frequently eat outside home, compared to $54.5 \%$ of females $(P<0.01)$. There were no significant differences between urban (60.1\%) and rural (58.9\%) areas. The foods eaten outside home is more likely to be high in total energy, total fat, saturated fat, cholesterol, and sodium but contain less fiber and calcium.

The increasing frequency of eating out at restaurants and eating food prepared away from home may be attributed to several factors: more women are involved in the workforce, and thus they have less time available for food preparation at home. The increase in per capita income especially in Arab Gulf countries; the lack of places to spend leisure time, for many families, dinning at restaurants has become their favorite pastime activity during weekend and holidays [47].

Worldwide, the portion sizes of foods prepared outside the home have been increasing both in prepacked, ready-toeat products and at restaurants. For example, in 1916, a soft drink bottle was sold in 6-5 ounce (oz); in 1950s, a 10-oz and 12-oz bottle was available. Today, soft drinks intended for individual consumption are sold in 20 or 32-oz bottles. Fast foods restaurants typically offer a range of portion sizes, from small through to super-sized items [89].

Studies related to obesity with eating out in the EMR are very limited. In Saudi Arabia, Amin et al. [90] found that as eating outside the home increased in primary school children (6-11 years), the proportion of obesity increased. Among those who did not eat outside the home, 9.4\% were obese and the rest were nonobese. The proportion of obesity increased to reach $52.7 \%$ among those who eat outside the home for more than 5 times per week. The association between eating outside home and obesity among these children was highly statistically significant $(P<0.001)$. In Iran, Hejazi and Mazloom [91] studied nutrient intake from meals consumed away from home by adolescents (12-16 years), using 24 hours dietary recall. They found a significant differences on mean daily energy intake $(P=0.007)$ between adolescents who ate at least one meal away from home than who did not eat ( $1618 \mathrm{kcal}$ versus $1472 \mathrm{kcal}$, resp.).

4.8. Television Viewing. Several studies in the Western countries have indicated that there is a positive association between the amounts of time spent watching television and obesity among children [92]. Increased television viewing time, playing video games, and using the internet have been often cited as a contributing factor to the increased prevalence of sedentary behavior during leisure time, and therefore a decline in physical activity in Western countries [89].

In Saudi Arabia, it was found that obese preschool children (4-6 years) watched television significantly 
$(P<0.001)$ longer that nonobese $(197.5 \pm 89.3$ and $150.0 \pm 60.9$ minutes per day, resp.) [93]. In Egypt, it was shown that $38 \%$ of nonobese preschool children aged 4-6 years watched television more than 2 hours a day, compared to $50 \%$ of obese children [73]. A similar finding was reported in Iran for school children aged 11-18 years [65]. In that study, obese boys were significantly more likely to view television than nonobese peers (295 versus 245 minutes per day) $(P<0.04)$. In Iraq, Lafta and Kadhim [94] found that children aged 7-12 years, who watched TV more than 3 hours, were more prone to be obese than those who watched less than 3 hours/day (odd ratio 2.98, $P<0.001$ ).

Eating while watching television is another contributing factor for obesity. This may lead to overeating because the type and the amounts consumed food may be less well self-monitored [81]. Few data are available to address the association between television viewing and food intake in the EMR. The available data were either preliminary or represent a small sample size. In Bahrain, Al-Sendi [95] found that $57 \%$ of obese adolescents consumed their main meals (lunch and supper) while watching the television, compared to $46 \%$ of nonobese. In the Arab Gulf Countries, it was reported that chocolates, sweets, potato chips, soft drinks, and nuts were the main foods consumed while watching television by school children [47].

There has been a dramatic change in exposure to messages that encourage intake of high-energy foods. Exposure to food advertising, especially commercials for fast foods, soft drinks, sweets, and chocolates, may influence the viewer's food choices towards these foods [96]. In EMR, television is still the most widely used advertising medium, and, therefore, it has a high influence on the food habits of the people, particularly children [47]. In Bahrain, Musaiger [97] found that the main television food advertisements preferred by children (5-12 years) were fast foods (43\%), chocolate and sweets (41\%), milk (40\%), and soft drinks (38\%). In Egypt, Jaweesh [98] showed that television advertisements were the main source $(65 \%)$ of purchasing new chocolates and sweets by school children.

4.9. Physical Inactivity. Data on population-based physical activity in the EMR countries are very limited. Most of the available data are often difficult to interpret due to differences in the way physical activity is measured and due to absence of national or regional physical activity guidelines. However, low physical activity in the EMR countries was reported among children [93], adolescents [99, 100], and adults [101].

A study on measuring physical activity in obese and nonobese 8-12-year school boys in Saudi Arabia using pedometer concluded that the prevalence of inactivity among these boys was high (47\%). However, active boys showed significantly lower body fat percentage $(P<0.01)$ and BMI $(P<0.001)$ than inactive peers. Obese boys, on the other hand, were significantly less active than nonobese boys $(P<$ 0.001) [102].

In Iran, Kelishadi et al. [72] found that regular morning exercise was performed by school children at school, but there was no significant difference between girls and boys and between overweight or obese and other subjects for each sex. There was a significant difference with regard to regular physical activity according to the year at school $(P<0.03)$, as well as participation in sports teams between girls and boys $(P<0.02)$ and also between subjects with BMI lower or higher than the 85 th percentile for each sex $(P<0.04)$.

In Saudi Arabia, Al-Nozha et al. [103] reported a high prevalence of inactivity among adults (96\%). There was significantly $(P<0.001)$ more inactive females $(98.1 \%)$ than males $(93.9 \%)$. Inactivity prevalence increases with an increasing age category, especially in males, and decreases with increasing education levels. Inactivity was the highest in the central region (97.3\%) and lowest in the southern (94\%) region of Saudi Arabia. Furthermore, active individuals exhibited lower values of BMI and waist circumference. These findings indicate the sedentary nature of the Saudi population. The overwhelming majority of men and women did not reach the recommended physical activity levels necessary for promoting health and preventing diseases. The high prevalence of inactivity among Saudis represents a major public health concern.

Among adult Bahraini, a significant negative relationship was seen between walking and obesity $(P<0.01)$. In general, the majority of Bahraini adults (40-69 years) walk less than one kilometer on an average weekday (67\% and $94 \%$ of men and women, resp.) [104]. The prevalence of inactivity among most EMR countries is relatively high. Based on Stepwise surveys supervised by WHO/EMRO [105], the proportion of physical inactivity in selected countries in the Region ranged from $31 \%$ in Syrian to $86.8 \%$ in Sudan (Figure 2). In UAE, it was found that $58 \%$ of men and $75 \%$ of women were sedentary or inactive [106]. The high increase of using car for transportation may also be a contributing factor to the trend towards lower physical activity levels. More and more people are less likely to walk or bike compared to the previous two decades. There is a marked increase in ownership in cars in most middle- and high-income countries in the region [47]. Data on the relationship between the change in trends of occupation and occurrence of obesity in the region are relatively absent. However, demographic data for EMR countries showed that occupations requiring physical activity have declined to more sedentary occupation. There is a big shift away from heavy manual work such as farming, diving, carpentry, and animal husbandry to the service sector and high technology work that requires little energy expenditure [107].

4.10. Stunting. Stunting may be a possible risk factor for overweight in many developing countries, including EMR countries. Nutritional stunting may cause a serious of longlasting changes such as lower energy expenditure, higher susceptibility to the effects of high-fat diet, lower-fat oxidation, and impaired regulation of food intake [108]. El-Taguri et al. [15] analysed data on overweight and stunting from large national surveys performed between 2001 and 2004 in five countries in EMR (Djibouti, Libyan Arab Jamahiriya, Morocco, Syrian Arabian Republic and Yemen). Overweight and stunting were defined according to recent WHO growth 


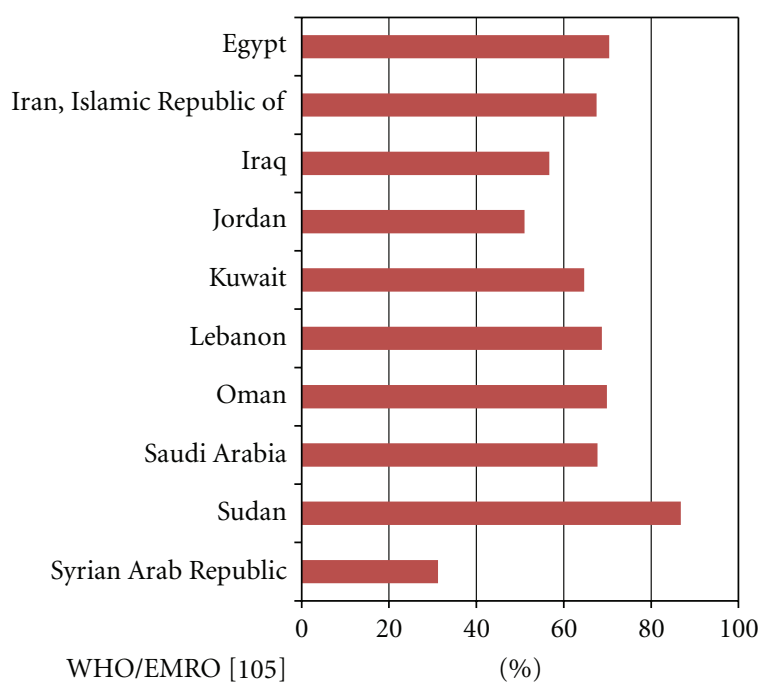

Figure 2: Prevalence of physical inactivity among adults in selected countries of the Eastern Mediterranean Region.

standards. The risk ratios for overweight in stunted children were $2.14,3.85,2.8,3.56$, and 2.63 in these five countries, respectively. Stunted children have impaired the regulation of food intake and have higher susceptibility to the effects of high-fat diet. When energy intake improves, deposition of fat overtime, especially in the abdomen, may result [15].

4.11. Short Sleep Duration. Evidence has grown over the past decade supporting a role for short sleep duration as a novel risk factor for weight gain and obesity. A number of casual pathways linking reduced sleep with obesity have been posited based on experimental studies of sleep deprivation. Chronic partial sleep deprivation causes feelings of fatigue which may lead to reduced physical activity [109]. Sleep deprivation may also have neurohormonal effects that increases caloric intake. Because of the rapidly accelerating prevalence of sleep deprivation, any casual association between short sleep duration and obesity would have substantial importance from a public health standpoint [110].

Studies on the association between sleep duration and obesity in the EMR are at most scanty. Bawazeer et al. [111] aimed to investigate the relationship between sleep length and obesity in Saudi students. A total of 5,877 Saudi student, boys $(55.2 \%)$ and girls (44.8\%), aged between 10 and 19 years, were randomly selected from elementary, intermediate, and secondary schools in different regions of Riyadh. A questionnaire on sleep behaviors was given. Anthropometry included BMI and waist and hip circumferences. Sleeping for seven hours or less significantly increased the risk of obesity in both boys and girls (all age categories) (odds ratio $=1.25-1.38,95 \%$ confidence intervals $=1.02-1.89$ ). Overall, the prevalence of overweight and obesity was higher among those sleeping intermittently $(18.68 \%)$ than those sleeping continuously $(14.5 \%)(P=0.024)$. Short sleep duration and poor sleep quality are significantly associated with obesity among Arab youth. Future studies need to employ more objective measures of sleep, such as actigraphy, and examine the mechanism of these associations.

4.12. Body Image. Body image is an important underlying psychological factor associated with body weight. Overemphasis on slimness among adolescents can lead to unhealthy dieting practices and eating disorders, whereas underestimation of body weight may increase risk of the development of overweight and obesity. Perception of body shape appears to be highly influenced by cultural and social factors [4].

Body image dissatisfaction (BID) is defined as a subjective negative evaluation of one's physical appearance. In the United Arab Emirates (UAE), 66\% of adolescent girls (13-18 years) have the desire to be thin [112]. The prevalence of BID among adolescent girls in Pakistan was $11.4 \%$ [113]. In Jordan, Mousa et al. [114], found that 21\% of adolescent girls aged 10-16 years displayed body image dissatisfaction. Physical changes associated with puberty and the exhibiting of negative eating attitudes were associated with this dissatisfaction.

In Saudi Arabia, it was reported that $22.5 \%$ and $6.6 \%$ of normal weight women perceived themselves as overweight and obese, respectively, while $36.8 \%$ and $28 \%$ of overweight women were perceived themselves as normal weight and obese, respectively [86]. In Bahrain, Al-Sendi et al. [115] showed a significant discrepancy between adolescents' perception of body weight and actual BMI. There was a tendency to underestimate their weight status, which was especially noteworthy among the overweight and obese. More than half of the girls and about one-third of the boys expressed discontent with their current body weight. About (33.5\%) and $(26.6 \%)$ of the adolescents thought that their parents and their peers, respectively, would consider them to be overweight or obese. The percentage of adolescents who reported parental or peer underestimation was higher among those classified as overweight or obese than it was among those who were of normal weight. The study showed the existence of a distorted body image as reflected by failure of many overweight or obese adolescents to perceive themselves as such. Among Bahraini adolescents, weight-related beliefs and attitudes exist at two ends of the spectrum: a tolerance of obesity at one end and exaggerated concern for its occurrence at the other.

4.13. Cultural Factors. Cultural factors may play an important role in occurrence of obesity in some countries in the region. Studies on the association of culture with obesity in EMR countries are uncommon. In some Arab countries in the region, it has been proposed that western standard of beauty has contributed for preoccupation with thinness and body image dissatisfaction. Arab females, therefore, might be experiencing a growing conflict between Western values and Arabic tradition, attributing for occurrence of eating disorders in Arab Countries [116]. In Egypt, Nasser [117] compared two samples of Arab female students attending London and Cairo Universities. He found that $12 \%$ of Cairo 
group had eating disorders compared to $22 \%$ of London group. The study showed that concern with body weight existed in a society presumed to have different values. However, identification with Western cultural norms related to body image was thought to be partly responsible for causing high prevalence of eating disorder in London group. Al-Isa [118] reported that there may be a greater social pressure in Europe to be thin, perhaps, than in the Arab Gulf countries. He found that people in Kuwait there were a trend to tolerate fatness, and there were no social sanctions against adiposity.

The influence of men in determining women's attitudes towards body size is another important issue in some countries in the region. In Qatar, for example, about $43 \%$ of Arab women studied believed that men preferred plump women [119]. Similar findings were reported in Morocco, as there is a cultural preference of body fatness among women of the Sahraoui ethnic group [120]. In a study among those women in Morocco (one of the main four ethnic groups in the country), it was found that the majority (80\%) of these women describes their body as appropriate and socially acceptable, despite the prevalence of overweight $(30 \%)$ and obesity (40\%) among them. This may indicate that Sahraoui still have traditionally strong positive cultural views of large body sizes. The high prevalence of obesity among this ethnic group in Morocco explained by the combination of urbanization and cultural preferences of body fatness as they considered fatness a beauty criterion [121]. About $70 \%$ of South Morocco women had made a previous attempt to gain weight. Appetite stimulant, overeating, and corticosteroids were the main methods used to fatting. In addition, some women used traditional suppositories called Ligue, composed of dates mixed with seeds and medicinal part, specifically for increasing their peripheral fat [122]. It is believed that the preference for plumpness women in some regions in the EMR countries is due to sexual attraction, rather than any other factors. However, such conclusion needs to be studied [119]

The traditional dressing may indirectly contribute to obesity in some countries in the region. The traditional long and wide dress either for men or women in the Arab Gulf States, Sudan, and North African Countries may hid the fatness of people, and consequently reduce their motivation to lose weight [123]. The women in Iran mandated by law to wear full-body covering while in public. This covering makes it difficult to observe the size and shape of the female body, thereby, reducing the emphasis on these features and possibly acting a protective factor against eating disorders and body image concern [124].

Al-Tawil et al. [125] hypothesized that women who wear trousers and skirt in Iraq would be aware early on any increase in their weight, especially increase in their waist circumference, than women who wear loose grown or abaya (traditional long dress covering the whole body). They found that the proportion of obesity ( $\mathrm{BMI} \geq 25)$ was greater among women who wore grown at home than those who wore pyjamas $(P<0.024)$, but there was no significant difference with regard dressing grown and trousers $(P=0.294)$. However, the percentage of obesity was higher among those who wore grown or abaya, than those who wore trousers outside home ( $77.9 \%$ and $70.6 \%$, resp.).

Women in the region are facing more barriers to practicing physical activity than men. This is because men, in general, have more freedom and places to practice sport and other recreational activities [126]. In Bahrain, for example, the main sociocultural barriers to practicing physical activities perceived by women were home commitments (49\%), care of children (36\%), and negative attitudes by family members towards women practicing exercise/sport (24\%). Of the women studied, $67 \%$ believed that there is a sex discrimination, as sport and other recreational facilities are mostly provided for males [126].

After adjusting for age, income, and smoking, obese Saudi women were $50 \%$ more likely to be inactive than nonobese women (odd ratio 1.5, 95\% CI, 1.11-2.04). The investigators attributed the high prevalence of obesity among Saudi women to limited physical activity, as a result of the widely dependent on housemaids and the limited availability of exercising facilities for girls and women in Saudi Arabia [101]. Arab-Moghaddam et al. [127] reported that, the cultural based constraints suggested that Iranian women believed value was not placed for women and the traditions that restricted the freedom of women inhibited their leisure, including participating in sport activities.

Al-Tawil et al. [125] hypothesized that the cultural habit of eating from same plate by family members may affect the quantity of food eaten as it is neither measureable nor limited for each person. This may encourage some family members to eat more. They found that the prevalence of obesity (BMI > 25) among those who shared the plate with the family members was higher $(77.5 \%)$ than those who had individual plates $(69.4 \%)$, but the difference was not statistically significant $(P=0.592)$.

4.14. Food Subsidy Policy. There is a growing indications that food prices subsidy policy may participate in increasing the weight of low social class due to high dependence on energy-dense subsidized foods $[128,129]$. Most of the EMR countries subsidized many food items such as wheat, rice, vegetable oil, and sugar. Some countries, such as Bahrain, subsidize red meat but not chicken or fish [130]. These foods are available with low cost; in addition, exercising has become very expensive both in terms of direct cost (fees) and opportunity cost of leisure time. This implies to suggest that such factor can lead to decrease in the relative costs of obesity, which means that the current satisfaction from eating more and exercising less is higher than the cost of maintaining a lower body weight and the future health costs associated with obesity [131].

Asfaw [131] examined the impact of the Egyptian food subsidy programme on mothers' weight. The study revealed that, mothers' BMI is inversely related to the price of subsidized energy-dense food and directly to the price of a high diet quality but expensive food items, suggesting that the programme aggravates obesity by lowering the direct cost of becoming obese. He also examined the consumption patterns of obese and nonobese mothers and found that the 
per capita calorie availability per day was almost the same between the two groups. However, a significant variation was observed in the number and value of foods given as a charity and number of guests ate and meals served, as they were 2.4 and 2.7 times higher in nonobese than obese households. This suggests that the actual energy consumption by mothers in nonobese household was less likely than in obese household.

4.15. Other Factors. There are many other factors, which may be linked with obesity but have not been well investigated, such as multiparity, home environment, sociopsychological factors, school environment, beliefs and attitudes, educational status, and cultural factors.

\section{Conclusion}

Studies in developing countries indicate that obesity has become one of the main public health problem, which needs an instant action to prevent and control [132, 133]. Obesity has become an epidemic in most of countries of the Eastern Mediterranean Region, requiring urgent action to combat this epidemic.

There are several dietary, social, lifestyle, and cultural factors associated with obesity in this region. In general, comprehensive and in-depth studies on the role of these factors in the occurrence of obesity are lacking. Most studies are cross-sectional with a limited sample size and covering only certain regions of the country (i.e., not nationally based).

There are no comprehensive, multisectoral programmes directed toward combating obesity in the EMR countries. There are some activities related to the prevention and control of obesity in several countries, mainly carried out by the Ministry of Health. Most of these activities focus on producing booklets, and on education through the mass media.

There is a need to standardize the methodology used for studying obesity in the community including production of guidelines and measurement manual. There is also a need to establish physical activity guidelines in the region. These guidelines should include specific recommendations on physical activity by age and sex, taking into consideration the social and cultural norms of each EMR country. Since this region has its own sociodemographic characteristics, further studies on sociocultural factors associated with obesity should be carried out to help in better understanding of the causes of obesity. Tribal and ethnic factors should also be considered as an area for studying in the region. The relationship between consanguineous marriage and obesity is another important area of research, as this phenomenon is widely spread in this region.

There is a severe shortage of studies related to childhood obesity in the EMR countries and a need to carry out national-base studies on overweight and obesity among preschoolers, schoolchildren, and adolescents. Several factors should be considered when planning for such studies: (1) the use of standardized age ranges, (2) the use of a standardized cut-off for measuring overweight and obesity, (3) inclusion of waist circumference in addition to BMI as it is more sensitive indicator for measuring obesity, (4) the use of a standardized questionnaire that will enable the comparison of data between EMR countries, (5) the questionnaire should include information related to lifestyle, physical activity, and dietary habits of children, and (6) the inclusion of private schools (as most studies have been focused on public schools). A good example of this suggestion is the Arab Teens Lifestyle study (ATLS) project which was carried out in 10 cities of the region, using one standardized procedure and valid instrument. The aim of this project was to assess the physical activity patterns, sedentary activity, and dietary habits. The project was comprised of two stages: firstly, the cities in Bahrain, Kuwait, Saudi Arabia, UAE, Jordan, and Iraq. The second stage will include cities in Morocco, Tunisia, Oman, and Yemen [134].

There is a need to prepare a practical manual on how to prevent and control obesity in the community, targeting health workers and other related professionals. An example of such a manual is that prepared by the Arab Center for Nutrition [135], which focuses on the measurement of obesity and how to control it using dietary, physical activity, lifestyle modification, drugs, and surgical approaches.

\section{References}

[1] A. O. Musaiger, "Overweight and obesity in the Eastern Mediterranean Region: can we control it?" Eastern Mediterranean Health Journal, vol. 10, no. 6, pp. 789-793, 2004.

[2] A. M. Sibai, L. Nasreddine, A. H. Mokdad, N. Adra, M. Tabet, and N. Hwalla, "Nutrition transition and cardiovascular disease risk factors in Middle East and North Africa countries: reviewing the evidence," Annals of Nutrition and Metabolism, vol. 57, no. 3-4, pp. 193-203, 2010.

[3] C. L. Ogden, S. Z. Yanovski, M. D. Carroll, and K. M. Flegal, "The epidemiology of obesity," Gastroenterology, vol. 132, no. 6, pp. 2087-2102, 2007.

[4] World Health Organization (WHO), "Obesity and managing the global epidemic," WHO Technical Report Series 894, WHO, Geneva, Switzerland, 1998.

[5] World Health Organization (WHO), "Physical status: the use and interpretation of anthropometry," WHO Technical Report Series 854, WHO, Geneva, Switzerland, 1995.

[6] T. J. Cole, M. C. Bellizzi, K. M. Flegal, and W. H. Dietz, "Establishing a standard definition for child overweight and obesity worldwide: international survey," British Medical Journal, vol. 320, no. 7244, pp. 1240-1243, 2000.

[7] A. Must, G. E. Dallal, and W. H. Dietz, "Reference data for obesity: 85th and 95th percentiles of body mass index (wt/ht ${ }^{2}$ ) and triceps skinfold thickness," American Journal of Clinical Nutrition, vol. 53, no. 4, pp. 839-846, 1991.

[8] World Health Organization (WHO), "The WHO Child Growth Standards," http://www.who.int/childgrowth/en/.

[9] Center for Disease Control (CDC), "CDC growth charts for the United States: method and development," Series Report 11, no. 246, Atlanta, Ga, USA, 2000.

[10] R. I. Kosti and D. B. Panagiotakos, "The epidemic of obesity in children and adolescents in the world," Central European Journal of Public Health, vol. 14, no. 4, pp. 151-159, 2006.

[11] WHO, "Global Health Observatory Data," http://apps.who .int/ghodata/. 
[12] H. M. Al-Hazzaa, "Prevalence and trends in obesity among school boys in Central Saudi Arabia between 1988 and 2005," Saudi Medical Journal, vol. 28, no. 10, pp. 1569-1574, 2007.

[13] M. de Onis and M. Blossner, "Prevalence and trends of overweight among preschool children in developing countries," American Journal of Clinical Nutrition, vol. 72, no. 4, pp. 1032-1039, 2000.

[14] G. Y. Al-Raees, M. A. Al-Amer, A. O. Musaiger, and R. D'Souza, "Prevalence of overweight and obesity among children aged 25 years in Bahrain: a comparison between two reference standards," International Journal of Pediatric Obesity, vol. 4, no. 4, pp. 414-416, 2009.

[15] A. El Taguri, F. Besmar, A. Abdel Monem, I. Betilmal, C. Ricour, and M. F. Rolland-Cachera, "Stunting is a major risk factor for overweight: results from national surveys in 5 Arab countries," Eastern Mediterranean Health Journal, vol. 15, no. 3, pp. 549-562, 2009.

[16] Administration of Food and Nutrition, "Kuwait Nutritional Surveillance System," Ministry of Health, Kuwait, 2005.

[17] D. Alasfoor and A. J. Mohammed, "Implications of the use of the new WHO growth charts on the interpretation of malnutrition and obesity in infants and young children in Oman," Eastern Mediterranean Health Journal, vol. 15, no. 4, pp. 890-898, 2009.

[18] A. A. Kamal, A. Bener, and A. M. A. K. Al-Mulla, "Growth pattern of Qatari preschool children," Croatian Medical Journal, vol. 45, no. 4, pp. 461-465, 2004.

[19] FAO, "Nutrition Country profile-Sudan," Food and Nutrition Division, FAO, 2005.

[20] ONEP/UNICEF, MICS 111 Survey in 2006, Ministry of Public Health, National Office of Population and Family, Tunisia, 2007.

[21] T. Lobstein, L. Baur, and R. Uauy, "Obesity in children and young people: a crisis in public health," Obesity Reviews, Supplement, vol. 5, no. 1, pp. 4-104, 2004.

[22] A. M. Al-Sendi, P. Shetty, and A. O. Musaiger, "Prevalence of overweight and obesity among Bahraini adolescents: a comparison between three different sets of criteria," European Journal of Clinical Nutrition, vol. 57, no. 3, pp. 471-474, 2003.

[23] Z. Bader, A. O. Musaiger, K. Al-Roomi, and R. D'Souza, "Overweight and obesity among adolescent in Bahrain," Anthropologischer Anzeiger, vol. 66, no. 4, pp. 401-408, 2008.

[24] National Nutrition Institute, "Diet, Nutrition and Prevention of chronic Non-communicable Diseases among Egyptian Adolescents," Ministry of Health, Cairo, Egypt, 2008.

[25] R. Kelishadi, G. Ardalan, R. Gheiratmand et al., "Thinness, overweight and obesity in a national sample of Iranian children and adolescents: CASPIAN Study," Child: Care, Health and Development, vol. 34, no. 1, pp. 44-54, 2008.

[26] I. El-Bayoumy, I. Shady, and H. Lotfy, "Prevalence of obesity among adolescents (10 to 14 years) in Kuwait," Asia-Pacific Journal of Public Health, vol. 21, no. 2, pp. 153-159, 2009.

[27] A. M. Sibai, N. Hwalla, N. Adra, and B. Rahal, "Prevalence and covariates of obesity in Lebanon: findings from the first epidemiological study," Obesity Research, vol. 11, no. 11, pp. 1353-1361, 2003.

[28] A. Bener and A. A. Kamal, "Growth patterns of Qatari school children and adolescent aged 6-18 years," Journal of Health, Population and Nutrition, vol. 23, no. 3, pp. 250-258, 2005.

[29] M. I. El Mouzan, P. J. Foster, A. S. Al Herbish et al., "Prevalence of overweight and obesity in Saudi children and adolescents," Annals of Saudi Medicine, vol. 30, no. 3, pp. 203 208, 2010.
[30] H. Aounallah-Skhiri, H. B. Romdhane, P. Traissac et al., "Nutritional status of Tunisian adolescents: associated gender, environmental and socio-economic factors," Public Health Nutrition, vol. 11, no. 12, pp. 1306-1317, 2008.

[31] UAE-GSHS, "United Arab Emirates Global School-based Student Survey," AbuDhabi, United Arab Emirates, 2005.

[32] S. Yusuf, S. Hawken, S. Ônpuu et al., "Obesity and the risk of myocardial infarction in 27000 participants from 52 countries: a case-control study," The Lancet, vol. 366, no. 9497, pp. 1640-1649, 2005.

[33] Ministry of Health, "National Non-communicable Diseases Risk Factors Survey 2007," Bahrain, 2010.

[34] M. Janghorbani, M. Amini, W. C. Willett et al., "First nationwide survey of prevalence of overweight, underweight, and abdominal obesity in Iranian adults," Obesity, vol. 15, no. 11, pp. 2797-2808, 2007.

[35] Ministry of Health, "Risk Factors for Non-communicable Diseases in Kuwait," Kuwait, 2007.

[36] FAO, "Nutrition Country Profile-Libyan Arab Jamahiriya," Food and Nutrition Division, FAO, 2005.

[37] N. Mokhtar, J. Elati, R. Chabir et al., "Diet culture and obesity in northern Africa," Journal of Nutrition, vol. 131, no. 3, pp. 887S-892S, 2001.

[38] Ministry of Health, "National Health Survey, 2000, Vol 1: Study of Lifestyle Risk Factors," Oman, 2000.

[39] FAO, "Nutrition Country Profile-Palestine," Food and Nutrition Division, FAO, 2005.

[40] Ministry of Health, "Country-Specific Standard Report," Riyadh, Saudi Arabia, 2010.

[41] J. El-Ati, P. Traissac, B. Chiraz et al., "Change in nutritional status of adult women in Tunisia from 1996 to 2005: effect of living environment and socio-economic factors," International Journal of Obesity, vol. 32, supplement 1, p. S215, 2008.

[42] World Health Organization (WHO), "Diet, nutrition and prevention of chronic diseases," WHO Technical Report Series 916, WHO, Geneva, Switzerland, 2003.

[43] O. Galal, "Nutrition-related health patterns in the Middle East," Asia Pacific Journal of Clinical Nutrition, vol. 12, no. 3, pp. 337-343, 2003.

[44] S. W. Ng, S. Zaghloul, H. I. Ali, G. Harrison, and B. M. Popkin, "The prevalence and trends of overweight, obesity and nutrition-related non-communicable diseases in the Arabian Gulf States," Obesity Reviews, vol. 12, no. 1, pp. 113, 2011.

[45] S. Benjelloun, "Nutrition transition in Morocco," Public Health Nutrition, vol. 5, no. 1A, pp. 135-140, 2002.

[46] FAO, "Food Balance Sheet," 2009, http://faostat.fao.org/.

[47] A. O. Musaiger, Overweight and Obesity in the Arab Countries: the Need for Action, Arab Center for Nutrition, Bahrain, 2007.

[48] A. Esmaillzadeh and L. Azadbakht, "Major dietary patterns in relation to general obesity and central adiposity among Iranian women," Journal of Nutrition, vol. 138, no. 2, pp. 358363, 2008.

[49] M. Bes-Rastrollo, M. A. Martínez-González, A. SánchezVillegas, C. de la Fuente Arrillaga, and J. A. Martínez, "Association of fiber intake and fruit/vegetable consumption with weight gain in a Mediterranean population," Nutrition, vol. 22, no. 5, pp. 504-511, 2006.

[50] L. Nasreddine, A. Mehio-Sibai, M. Mrayati, N. Adra, and N. Hwalla, "Adolescent obesity in Syria: prevalence and associated factors," Child: Care, Health and Development, vol. 36, no. 3, pp. 404-413, 2010. 
[51] R. Kelishadi, G. Ardalan, R. Gheiratmand et al., "Association of physical activity and dietary behaviours in relation to the body mass index in a national sample of Iranian children and adolescents: CASPIAN Study," Bulletin of the World Health Organization, vol. 85, no. 1, pp. 19-26, 2007.

[52] S. El-Ghazali, J. M. Ibrahim, B. M. Kanari, and N. A. Ismail, "The relationship between lifestyle and body mass index among university students in Kuwait," Egyptian Journal of Community Medicine, vol. 28, pp. 69-76, 2010.

[53] S. Dastgiri, R. Mahdavi, H. TuTunchi, and E. Faramarzi, "Prevalence of obesity, food choices and socio-economic status: a cross-sectional study in the north-west of Iran," Public Health Nutrition, vol. 9, no. 8, pp. 996-1000, 2006.

[54] H. M. Niemeier, H. A. Raynor, E. E. Lloyd-Richardson, M. L. Rogers, and R. R. Wing, "Fast food consumption and breakfast skipping: predictors of weight gain from adolescence to adulthood in a nationally representative sample," Journal of Adolescent Health, vol. 39, no. 6, pp. 842-849, 2006.

[55] A. O. Musaiger and R. D’Souza, "Nutritional profile of local and western fast foods consumed in Bahrain," Ecology of Food and Nutrition, vol. 46, no. 2, pp. 143-161, 2007.

[56] C. A. Monteiro, E. C. Moura, W. L. Conde, and B. M. Popkin, "Socioeconomic status and obesity in adult populations of developing countries: a review," Bulletin of the World Health Organization, vol. 82, no. 12, pp. 940-946, 2004.

[57] H. N. Madanat, K. P. Troutman, and B. Al-Madi, "The nutrition transition in Jordan: the political, economic and food consumption contexts," Promotion \& Education, vol. 15, no. 1, pp. 6-10, 2008.

[58] O. M. Galal, "The nutrition transition in Egypt: obesity, undernutrition and the food consumption context," Public Health Nutrition, vol. 5, no. 1 A, pp. 141-148, 2002.

[59] H. Esmaeily, M. Azimi-Nezhad, M. Ghayour-Mobarhan et al., "Association between socioeconomic factors and obesity in Iran," Pakistan Journal of Nutrition, vol. 8, no. 1, pp. 53-56, 2009.

[60] H. F. Abdul-Rahim, G. Holmboe-Ottesen, L. C. M. Stene et al., "Obesity in a rural and an urban Palestinian West Bank population," International Journal of Obesity, vol. 27, no. 1, pp. 140-146, 2003.

[61] M. M. Al-Nozha, Y. Y. Al-Mazrou, M. A. Al-Maatouq et al., "Obesity in Saudi Arabia," Saudi Medical Journal, vol. 26, no. 5, pp. 824-829, 2005.

[62] F. Al-Awadi and E. K. Amine, "Overweight and obesity in Kuwait," Journal of the Royal Society of Health, vol. 109, no. 5, pp. 175-177, 1989.

[63] M. N. Ahmad, S. K. Tukan, and H. R. Takruri, "Obesity overweight in young adult females of northern Badia of Jordan," Malaysian Journal of Nutrition, vol. 12, no. 2, pp. 157-166, 2006.

[64] E. Ainy and F. Azizi, "Women, occupation and cardiovascular risk factors: findings from the Tehran Lipid and Glucose Study," Public Health, vol. 121, no. 12, pp. 950-953, 2007.

[65] A. O. Musaiger and E. Al-Ahdal, "Social and dietary factors associated with obesity among women in Saudi Arabia," in Obesity in the Arab World, A. O. Musaiger, Ed., Arab Center for Nutrition, Bahrain, 2010.

[66] A. O. Musaiger and M. Al-Ansari, "Factors associated with obesity among women in Bahrain," International Quarterly of Community Health Education, vol. 12, no. 2, pp. 129-136, 1992.

[67] J. S. Al-Malki, M. H. Al-Jaser, and A. S. Warsy, "Overweight and obesity in Saudi females of childbearing age," International Journal of Obesity, vol. 27, no. 1, pp. 134-139, 2003.
[68] A. Batnitzky, "Obesity and household roles: gender and social class in Morocco," Sociology of Health and Illness, vol. 30, no. 3, pp. 445-462, 2008.

[69] G. Veghari, M. Sedaghat, H. Joshaghani et al., "The prevalence of obesity and its related risk factor in the north of Iran in 2006," Journal of Research in Health Sciences, vol. 10, no. 2 , pp. 116-121, 2010.

[70] M. F. Fouad, S. Rastam, K. D. Ward, and W. Maziak, "Prevalence of obesity and its associated factors in Aleppo, Syria," Prevention and Control, vol. 2, no. 2, pp. 85-94, 2006.

[71] T. Harder, R. Bergmann, G. Kallischnigg, and A. Plagemann, "Duration of breastfeeding and risk of overweight: a metaanalysis," American Journal of Epidemiology, vol. 162, no. 5, pp. 397-403, 2005.

[72] R. Kelishadi, M. Hashemi Pour, N. Sarraf-Zadegan et al., "Obesity and associated modifiable environmental factors in Iranian adolescents: Isfahan healthy Heart program-heart health promotion from childhood," Pediatrics International, vol. 45, no. 4, pp. 435-442, 2003.

[73] T. M. Farahat, A. A. Mechael, and M. Abu-Salem, "Prevalence of obesity among preschool children in Menofia, Egypt," Arab Journal of Food and Nutrition, vol. 8, pp. 107-118, 2003.

[74] A. O. Musaiger and S. A. Hussein, "Breastfeeding and nutritional status in preschool children in Muharraq Governorate, Kingdom of Bahrain," Arab Journal of Food and Nutrition, vol. 7, no. 15, pp. 14-27, 2006.

[75] H. Fallahzadeh, M. Golestan, T. Rezvanian, and Z. Ghasemian, "Breast-feeding history and overweight in 11 to 13-year-old children in Iran," World Journal of Pediatrics, vol. 5, no. 1, pp. 36-41, 2009.

[76] N. Al-Qaoud and P. Prakash, "Breastfeeding and obesity among Kuwaiti preschool children," Medical Principles and Practice, vol. 18, no. 2, pp. 111-117, 2009.

[77] A. A. Bin Zaal, A. O. Musaiger, and R. D’Souza, “Dietary habits associated with obesity among adolescents in Dubai, United Arab Emirates," Nutricion Hospitalaria, vol. 24, no. 4, pp. 437-444, 2009.

[78] B. A. Swinburn, I. Caterson, J. C. Seidell, and W. P. T. James, "Diet, nutrition and the prevention of excess weight gain and obesity," Public Health Nutrition, vol. 7, no. 1A, pp. 123-146, 2004.

[79] A. Kerkadi, "Evaluation of nutritional status of United Arab Emirates University female students," Emirates Journal of Agricultural Science, vol. 12, no. 2, pp. 42-50, 2003.

[80] H. Szajewska and M. Ruszczyński, "Systematic review demonstrating that breakfast consumption influences body weight outcomes in children and adolescents in Europe," Critical Reviews in Food Science and Nutrition, vol. 50, no. 2, pp. 113-119, 2010.

[81] N. Yahia, A. Achkar, A. Abdallah, and S. Rizk, "Eating habits and obesity among Lebanese university students," Nutrition Journal, vol. 7, no. 1, article 32, 2008.

[82] F. B. Hu, "Sugar-sweetened soft drinks consumption and risk of type 2 diabetes and cardiovascular risk," CMR Journal, vol. 2, no. 2, pp. 15-18, 2009.

[83] G. A. Bray, "Soft drinks and obesity: the evidence," CMR Journal, vol. 2, no. 2, pp. 10-14, 2009.

[84] A. Sayegh, E. L. Dini, R. D. Holt, and R. Bedi, "Food and drink consumption, sociodemographic factors and dental caries in 4-5-year-old children in Amman, Jordan," British Dental Journal, vol. 193, no. 1, pp. 37-42, 2002.

[85] M. N. Ahmed and M. A. Darawshah, "Anthropometric indicators of overweight and obesity and dietary habits of 
school children 6-12 years in Jordan," Arab Journal of Food and Nutrition, vol. 3, pp. 225-240, 2002.

[86] P. Rasheed, "Perception of body weight and self-reported eating and exercise behaviour among obese and non-obese women in Saudi Arabia," Public Health, vol. 112, no. 6, pp. 409-414, 1998.

[87] A. O. Musaiger, "Obesity in the Arab Countries: prevalence, causes and prevention," in Obesity in Arab Countries, A. O. Musaiger, Ed., pp. 10-25, Arab Center for Nutrition, Bahrain, 2010.

[88] H. N. Bashour, "Survey of dietary habits of in-school adolescents in Damascus, Syrian Arab Republic," Eastern Mediterranean Health Journal, vol. 10, no. 6, pp. 853-862, 2004.

[89] S. A. French, M. Story, and R. W. Jeffery, "Environmental influences on eating and physical activity," Annual Review of Public Health, vol. 22, pp. 309-335, 2001.

[90] T. T. Amin, A. I. Al-Sultan, and A. Ali, "Overweight and obesity and their association with dietary habits, and sociodemographic characteristics among male primary school children in Al-Hassa, Kingdom of Saudi Arabia," Indian Journal of Community Medicine, vol. 33, no. 3, pp. 172-181, 2008.

[91] N. Hejazi and Z. Mazloom, "Socioeconomic status, youth's eating patterns and meals consumed away from home," Pakistan Journal of Biological Sciences, vol. 12, no. 9, pp. 730733, 2009.

[92] M. Caroli, L. Argentieri, M. Cardone, and A. Masi, "Role of television in childhood obesity prevention," International Journal of Obesity, vol. 28, no. 3, pp. S104-S108, 2004.

[93] H. M. Al-Hazzaa and A. A. Al-Rasheedi, "Adiposity and physical activity levels among preschool children in Jeddah, Saudi Arabia," Saudi Medical Journal, vol. 28, no. 5, pp. 766773, 2007.

[94] R. K. Lafta and M. J. Kadhim, "Childhood obesity in Iraq: prevalence and possible risk factors," Annals of Saudi Medicine, vol. 25, no. 5, pp. 389-393, 2005.

[95] A. Al-Sendi, Factor Determining Obesity among Adolescents in Bahrain, PH.D. desertation, London School of Tropical Medicine, London, UK, 2002.

[96] H. N. Madanat, R. B. Brown, and S. R. Hawks, "The impact of body mass index and Western advertising and media on eating style, body image and nutrition transition among Jordanian women," Public Health Nutrition, vol. 10, no. 10, pp. 1039-1046, 2007.

[97] A. O. Musaiger, The Influence of Television on Children's Habits, Bahrain Center for Studies and Research, Bahrain, 2004.

[98] K. S. Jaweesh, "Television advertisements as a factor influencing children food habits," Arab Journal of Food and Nutrition, vol. 3, no. 6, pp. 392-408, 2002.

[99] C. J. K. Henry, H. J. Lightowler, and H. M. Al-Hourani, "Physical activity and levels of inactivity in adolescent females ages 11-16 years in the United Arab Emirates," American Journal of Human Biology, vol. 16, no. 3, pp. 346353, 2004.

[100] A. Fazah, C. Jacob, E. Moussa, R. El-Hage, H. Youssef, and P. Delamarche, "Activity, inactivity and quality of life among Lebanese adolescents," Pediatrics International, vol. 52, no. 4, pp. 573-578, 2010.

[101] M. A. Alsaif, I. A. Hakim, R. B. Harris et al., "Prevalence and risk factors of obesity and overweight in adult Saudi population," Nutrition Research, vol. 22, no. 11, pp. 12431252, 2002.
[102] H. M. Al-Hazzaa, "Pedometer-determined physical activity among obese and non-obese 8- to 12-year-old Saudi schoolboys," Journal of Physiological Anthropology, vol. 26, no. 4, pp. 459-465, 2007.

[103] M. M. Al-Nozha, H. M. Al-Hazzaa, M. R. Arafah et al., "Prevalence of physical activity and inactivity among Saudis aged 30-70 years: a population-based cross-sectional study," Saudi Medical Journal, vol. 28, no. 4, pp. 559-568, 2007.

[104] F. Al-Mahroos and K. Al-Roomi, "Obesity among adult Bahraini population: impact of physical activity and educational level," Annals of Saudi Medicine, vol. 21, no. 3-4, pp. 183-187, 2001.

[105] WHO/EMRO, "Regional data on non-communicable diseases," 2009, http://www.emro.who.int/ncd/.

[106] P. Badrinath, Q. A. Al-Shboul, T. Zoubeidi et al., "Measuring the health of the nation: united Arab Emirates Health and Lifestyle Survey 2000," Faculty of Medicine and Health Sciences and College of Business and Economics, Al Ain, United Arab Emirates, 2002.

[107] A. Bener, "Colon cancer in rapidly developing countries: review of the lifestyle, dietary, consanguinity and hereditary risk factors," Oncology Reviews, vol. 5, no. 1, pp. 1-11, 2010.

[108] A. L. Sawaya, "Stunting and future risk of obesity: principal physiological mechanism," Cad Saude Publica Janeiro, vol. 19, pp. S21-S28, 2003.

[109] F. P. Cappuccio, F. M. Taggart, N. B. Kandala et al., "Metaanalysis of short sleep duration and obesity in children and adults," Sleep, vol. 31, no. 5, pp. 619-626, 2008.

[110] S. R. Patel and F. B. Hu, "Short sleep duration and weight gain: a systematic review," Obesity, vol. 16, no. 3, pp. 643653, 2008.

[111] N. M. Bawazeer, N. M. Al-Daghri, G. Valsamakis et al., "Sleep duration and quality associated with obesity among Arab children," Obesity, vol. 17, no. 12, pp. 2251-2253, 2009.

[112] V. Eapen, A. A. Mabrouk, and S. Bin-Othman, "Disordered eating attitudes and symptomatology among adolescent girls in the United Arab Emirates," Eating Behaviors, vol. 7, no. 1, pp. 53-60, 2006.

[113] D. B. Mumford, A. M. Whitehouse, and I. Y. Choudry, "Survey of eating disorders in English-medium schools in Lahore, Pakistan," International Journal of Eating Disorders, vol. 11, no. 2, pp. 173-184, 1992.

[114] T. Y. Mousa, R. H. Mashal, H. A. Al-Domi, and M. A. Jibril, "Body image dissatisfaction among adolescent schoolgirls in Jordan," Body Image, vol. 7, no. 1, pp. 46-50, 2010.

[115] A. M. Al-Sendi, P. Shetty, and A. O. Musaiger, "Body weight perception among Bahraini adolescents," Child: Care, Health and Development, vol. 30, no. 4, pp. 369-376, 2004.

[116] T. Y. Mousa, H. A. Al-Domi, and R. H. Mashal, "Eating disturbances in adolescent girls (a review)," Dirasat. Agricultural Sciences, vol. 36, no. 2, pp. 109-121, 2009.

[117] M. Nasser, "Comparative study of the prevalence of abnormal eating attitudes among Arab female students of both London and Cairo Universities," Psychological Medicine, vol. 16, no. 3, pp. 621-625, 1986.

[118] A. N. Al-Isa, "Dietary and socio-economic factors associated with obesity among Kuwaiti college men," British Journal of Nutrition, vol. 82, no. 5, pp. 369-374, 1999.

[119] A. O. Musaiger, N. E. Shahbeek, and M. Al-Mannai, "The role of social factors and weight status in ideal body-shape preferences as perceived by Arab women," Journal of Biosocial Science, vol. 36, no. 6, pp. 699-707, 2004. 
[120] M. Rguibi and R. Belahsen, "Overweight and obesity among urban Sahraoui women of South Morocco," Ethnicity and Disease, vol. 14, no. 4, pp. 542-547, 2004.

[121] M. Rguibi and R. Belahsen, "Body size preferences and sociocultural influences on attitudes towards obesity among Moroccan Sahraoui women," Body Image, vol. 3, no. 4, pp. 395-400, 2006.

[122] M. Rguibi and R. Belahsen, "Fattening practices among Moroccan Saharawi women," Eastern Mediterranean Health Journal, vol. 12, no. 5, pp. 619-624, 2006.

[123] A. O. Musaiger and K. Qashqari, "The relation between dressing and obesity among women in Saudi Arabia," Arab Journal of Food and Nutrition, vol. 6, pp. 292-302, 2005.

[124] P. Abdollahi and T. Mann, "Eating disorder symptoms and body image concerns in Iran: comparisons between Iranian women in Iran and in America," International Journal of Eating Disorders, vol. 30, no. 3, pp. 259-268, 2001.

[125] N. G. Al-Tawil, M. M. Abdulla, and A. J. Abdul Ameer, "Prevalence of and factors associated with overweight and obesity among a group of Iraqi women," Eastern Mediterranean Health Journal, vol. 13, no. 2, pp. 420-429, 2007.

[126] A. O. Musaiger and M. S. Al-Ansari, "Barriers to practicing physical activity in the Arab countries," in Nutrition and Physical Activity in the Arab Countries of the Near East, A. O. Musaiger and S. S. Meladi, Eds., FAO/Cairo Regional Office, Cairo, Egypt, 2000.

[127] N. Arab-Moghaddam, K. A. Henderson, and R. Sheikholeslami, "Women's leisure and constraints to participation: Iranian perspectives," Journal of Leisure Research, vol. 39, no. 1, pp. 109-126, 2007.

[128] L. M. Powell and F. J. Chaloupka, "Food prices and obesity: evidence and policy implications for taxes and subsidies," Milbank Quarterly, vol. 87, no. 1, pp. 229-257, 2009.

[129] A. Asfaw, "The role of food price policy in determining the prevalence of obesity: evidence from Egypt," Review of Agricultural Economics, vol. 28, no. 3, pp. 305-312, 2006.

[130] A. Aoyama, Toward a Virtuous Circle: A Nutrition Review of the Middle East and North Africa; World Bank Human Development Network, The World Bank, Washington, DC, USA, 1999.

[131] A. Asfaw, "Do government food price policies affect the prevalence of obesity? Empirical evidence from Egypt," World Development, vol. 35, no. 4, pp. 687-701, 2007.

[132] A. M. Prentice, "The emerging epidemic of obesity in developing countries," International Journal of Epidemiology, vol. 35, no. 1, pp. 93-99, 2006.

[133] C. Papandreou, T. A. Mourad, C. Jildeh et al., "National prevalence of obesity: obesity in Mediterranean region (1997-2007): a systemic review," Obesity Reviews, vol. 9, pp. 389-399, 2008.

[134] H. M. Al-Hazzaa, A. O. Musaiger, and ATLS Group, "Physical activity patterns and eating habits of adolescents living in major Arab cities. The Arab Teens Lifestyle Study," Saudi Medical Journal, vol. 31, no. 2, pp. 210-211, 2010.

[135] Arab Center for Nutrition, "Manual on Management of Obesity," Bahrain, 2008. 


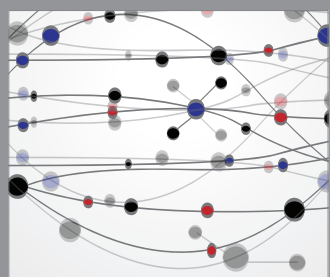

The Scientific World Journal
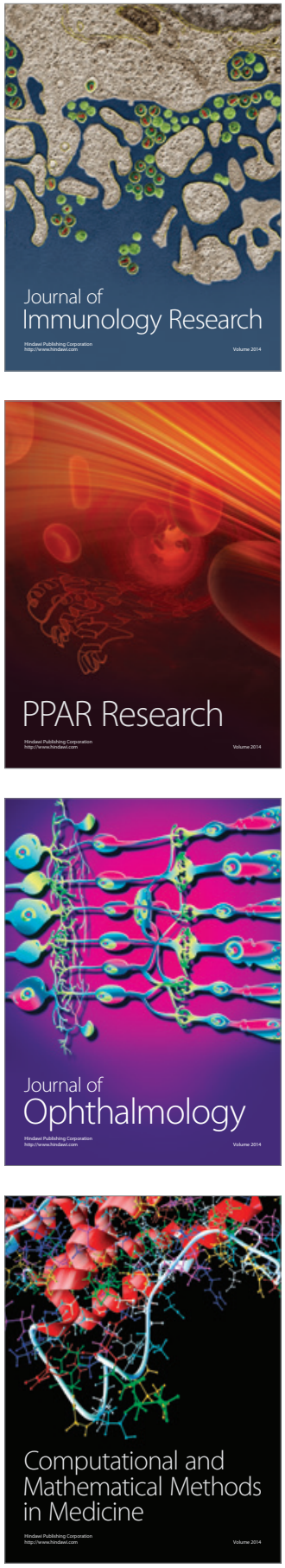

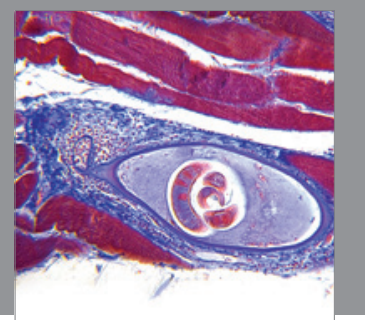

Gastroenterology

Research and Practice
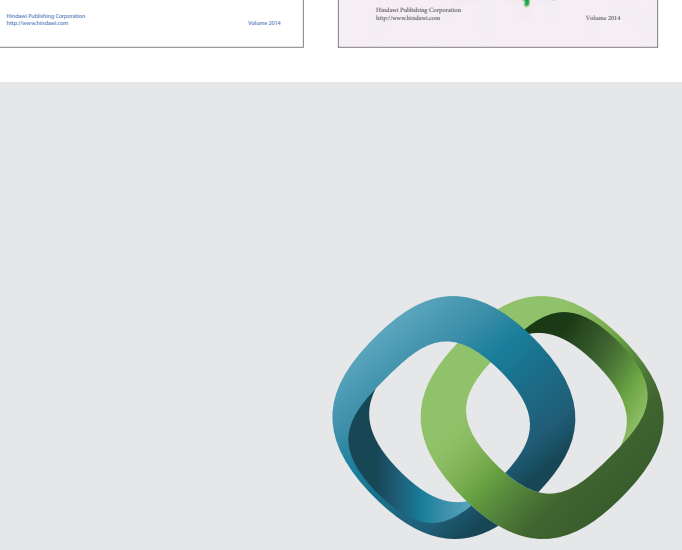

\section{Hindawi}

Submit your manuscripts at

http://www.hindawi.com
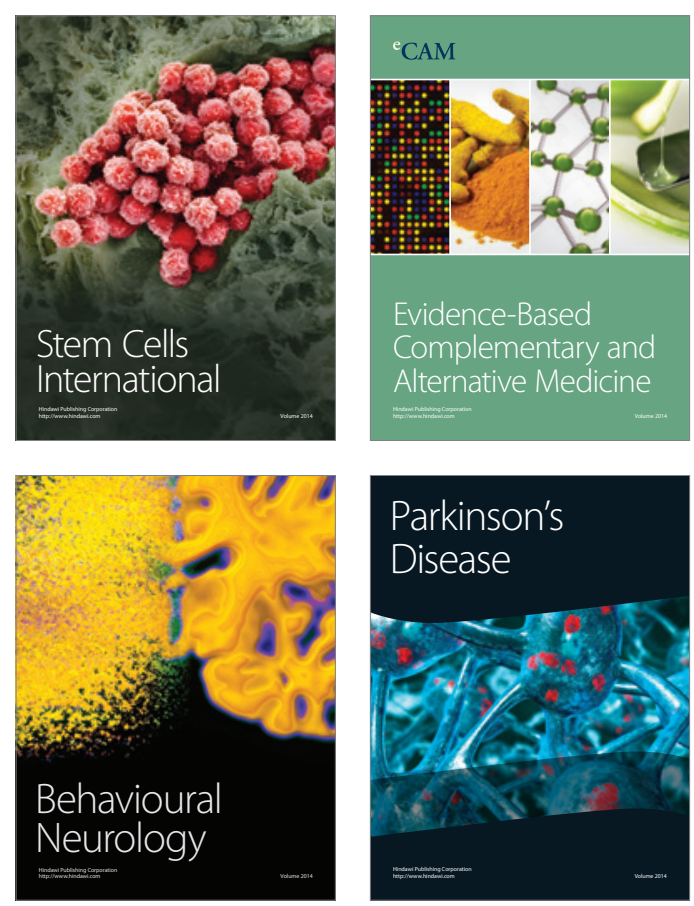

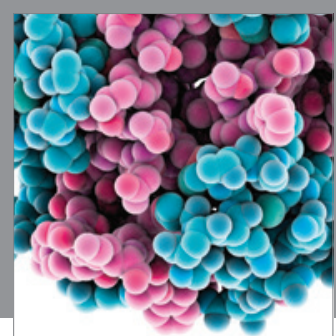

Journal of
Diabetes Research

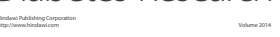

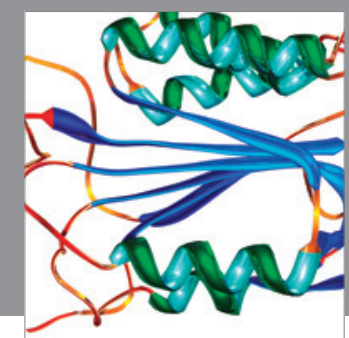

Disease Markers
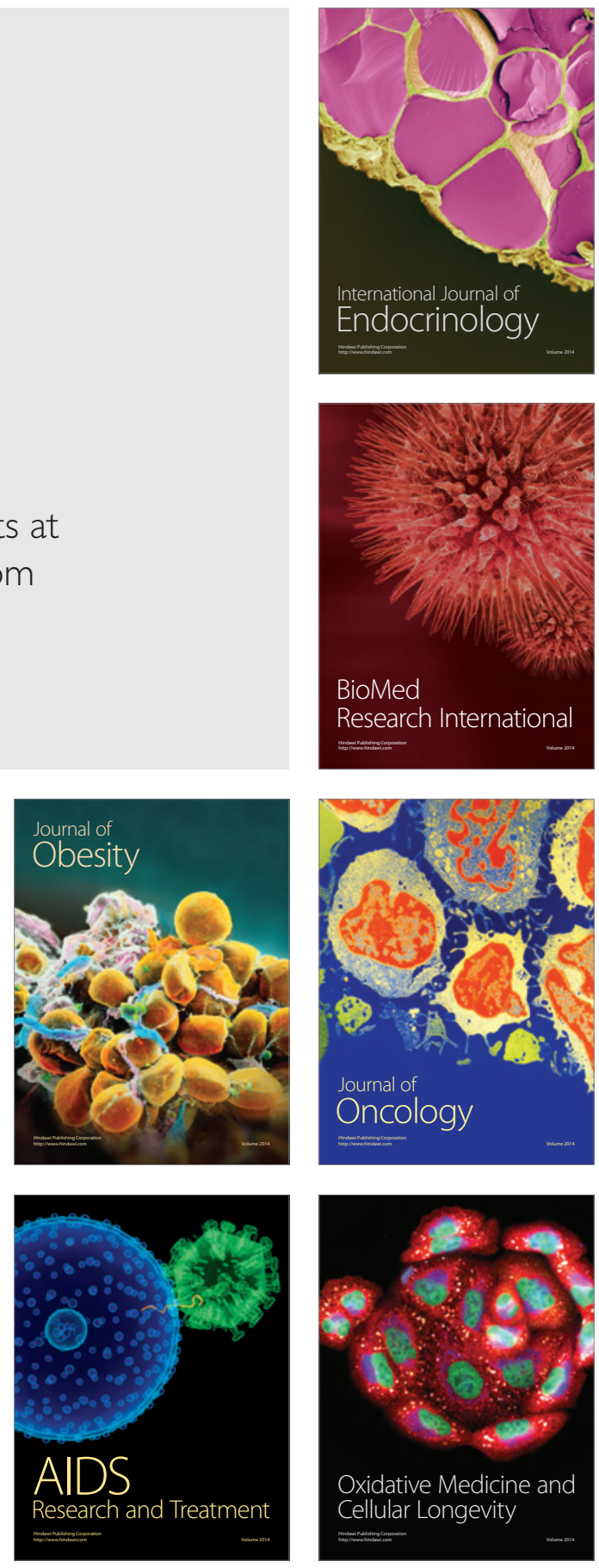